\title{
Efeitos macroeconômicos e setoriais das subvenções da Finep no Brasil
}

* Domitila Santos Babia (D)

Universidade Federal de Juiz de Fora (UFJF), Juiz de Fora (MG), Brasil

E-mail: domitilabahia@gmail.com

** Eduardo Gonçalves

Universidade Federal de Juiz de Fora (UFJF), Juiz de Fora (MG), Brasil

E-mail: eduardo.goncalves@uff.edu.br

*** Admir Antônio Betarelli Jr.

Universidade Federal de Juiz de Fora (UFJF), Juiz de Fora (MG), Brasil

E-mail: abetarelli@gmail.com

Submissấ: 13 de Outubro de 2020 Versāo revisada (entregue): io de FeVereiro de 202 I Aprovado: 2 de Junho de 202 I

\section{Resumo}

Políticas de fomento à pesquisa e desenvolvimento (P\&D), como as subvençôes à inovação, têm ganhado atenção em diversas economias por contribuirem para o crescimento econômico e competitividade dos setores domésticos. Os impactos dessas políticas são espraiados sistemicamente pela economia e, para analisá-los, este trabalho apresenta um modelo de equilíbrio geral computável que, pelo tratamento diferenciado do capital de conhecimento e do investimento em P\&D, é capaz de avaliar os efeitos macroeconômicos e setoriais das subvençóes. Os resultados indicam que as subvençóes geram ganhos de capital de conhecimento e, analogamente, sua ausência retrai as atividades industriais e penaliza a capacidade produtiva dos setores de maior intensidade tecnológica.

Palavras-chave | Subvenções econômicas; Finep; Políticas de inovação; Equilíbrio Geral Computável. 


\title{
Macroeconomic and sectoral effects of Finep grants in Brazil
}

\begin{abstract}
Public policies to promote research and development (R\&D), such as subsidies for innovation, have gained attention in several economies because they induce the competitiveness of the productive structure. The impacts of these policies are systematically spread by the economy, and to analyze them, this paper presents a computable general equilibrium model that, due to the different treatment of knowledge capital and investment in R\&D, is able to assess the macroeconomic and sectoral effects of the grants. The results indicate that the grants generate knowledge capital gains and, similarly, their absence retracts industrial activities of greater technological intensity, penalizing their productive capacity.

Keywords | Economic subsidies; Finep; Innovation policies; General Computable Equilibrium.
\end{abstract}




\section{Introdução}

Políticas públicas de fomento à inovação ganharam espaço na agenda de incentivos ao setor produtivo privado nos últimos trinta anos. No Brasil, houve avanços legais visando estimular intensivamente o progresso tecnológico no setor privado, para criar um ambiente institucional favorável à interação entre os agentes das instituições científicas, tecnológicas e de inovação (ICTs) e o setor produtivo. Especificamente, houve estímulos de inovação nas empresas como as subvenções econômicas, financiamentos diretos, incentivos fiscais, entre outros instrumentos (BRASIL, 2004), sendo diretrizes de política de inovação até 2016.

A subvenção econômica configurou-se em um dos principais instrumentos dessa política a fim de incentivar a inovação nas empresas. O programa de concessão de subvençóes previa a cobertura de despesas de custeio de projetos de $\mathrm{P} \& \mathrm{D}$ de produtos e processos inovadores de empresas brasileiras, independentemente da origem de seu capital, tendo como missão dividir os riscos e os custos inerentes ao processo de inovação, não requerendo retorno dos recursos ao Estado. O presente trabalho propóe-se a analisar os impactos das concessóes de subvençóes à inovaçáo na economia brasileira, visando os efeitos macroeconômicos e setoriais de longo prazo no Brasil.

Existem evidências empíricas de efeitos positivos de algumas políticas de fomento à inovação mediante incentivos fiscais e financeiros sobre a produtividade e competitividade da economia (e.g., AVELLAR; ALVES, 2008; AVELLAR, 2009; COELHO; DE NEGRI, 2011; KANNEBLEY; PORTO, 2012; ARAÚJO et al., 2012). Tais pesquisas sobre os efeitos das políticas brasileiras no nível de investimento em P\&D geraram resultados relevantes acerca da efetividade dos mecanismos utilizados, no entanto, questiona-se também sua capacidade de estimular as empresas a ampliarem seus investimentos próprios em atividades tecnológicas e, com isso, acelerar o ritmo da inovação no país. Como se trata de estudos de equilíbrio parcial, tais aplicaçōes econométricas produzem estimativas e/ou projeções incompletas justamente por não abordarem a complexidade das interaçôes sistêmicas na economia.

Ao considerar o conhecimento na forma de fator primário do sistema produtivo brasileiro em um modelo de equilíbrio geral computável, é possível inseri-lo nas discussōes sobre crescimento econômico. Indicadores como produção agregada, renda, consumo, entre outros, seriam afetados positivamente pelo aumento do estoque de conhecimento na economia. Por isso, busca-se verificar como e em que 
intensidade o - programa de concessão de subvenções à inovação afeta os principais indicadores macroeconômicos e setoriais na economia brasileira.

Esse artigo contribui empiricamente desenvolvendo um modelo de equilíbrio geral computável (EGC) que incorpora de forma explícita o investimento em P\&D, com base no System of National Account (SNA 2008). Denominado BIM-KC (Brazilian Intersectoral Model with Knowledge Capital), o modelo aqui desenvolvido traz algumas contribuiçôes em relação aos modelos nacionais já construídos. Primeiro, adiciona em sua especificação teórica a distinção entre capital físico e capital de conhecimento (knowlegde capital). Segundo, incorpora explicitamente o capital de conhecimento como um fator de produção e o investimento em capital de conhecimento como componente da formação bruta de capital fixo da economia (FBCF). Terceiro, o modelo contribui para a literatura de Economia da Tecnologia ao evidenciar os impactos das subvenções econômicas à inovação, estabelecendo um vínculo entre a estrutura produtiva, os investimentos e a formação de capital na economia. Nesse sentido, com base nos valores das concessões de subvenção econômica da Financiadora de Estudos e Projetos (Finep) entre os anos de 2010 e 2016, a análise de EGC busca avaliar o comportamento das variáveis macroeconômicas e setoriais frente à influência da política de subvenção à inovação.

Os resultados alcançados pela aplicação do modelo BIM-KC na avaliaçẫo da política de concessões de subvenções à inovação do Governo Federal são provenientes de um cenário no qual tais concessóes não existem. Sob essa hipótese, parte-se do princípio de que os projetos de inovação das empresas continuariam sendo executados, mas seriam custeados por elas mesmas, alterando a estrutura de custos de produção na intenção de gerar inovação. Nesse tipo de exercício, de acordo com as características da metodologia empregada, os efeitos encontrados são resultados imediatos da simulação realizada e os resultados indiretos provenientes da observação dos encadeamentos intersetoriais do modelo de EGC.

Além desta introdução, este artigo apresenta mais seis seçôes. Nas segundas e terceiras seçóes abordam-se os elementos teóricos sobre o papel das políticas públicas de inovação e da revisão da literatura empírica sobre modelos de EGC. Na quarta, apresentam-se os aspectos gerais do modelo de equilíbrio geral empregado. $\mathrm{Na}$ quinta, estão as aplicaçóes do modelo, o cenário econômico de referência, os choques e simulaçóes pretendidos e, posteriormente, na sexta seção, mostram-se os resultados alcançados. 


\section{Políticas públicas, P\&D e inovação no Brasil}

A tradição neoclássica normalmente vê o papel da política pública como sendo o de corrigir falhas de mercado (CLARK; GUY, 1998). Desse modo, esse papel passivo limitaria a atuação do setor público no processo de pesquisa, desenvolvimento e inovação ao financiamento da pesquisa básica, setor no qual é gerado novo conhecimento (MAZZUCATO, 2014).

Espera-se que a política pública de inovação cubra uma ampla variedade de iniciativas que incentivem o setor privado na promoção da geraçáo de inovaçáo. Assim, a preocupação fundamental dos governos e dos policy makers passa a ser a identificação de qual instrumento de política é o mais apropriado para estimular as atividades tecnológicas do país, considerando o Estado não como substituto do mercado em suas falhas estáticas, mas sim como o agente auxiliador na alocação dos recursos. Portanto, a discussão dos motivos pelos quais o Estado precisa intervir na economia perde espaço para o debate sobre a forma de como ele deve intervir na promoção do desenvolvimento tecnológico (DOSI; PAVITT; SOETE, 1990).

A trajetória dos dispêndios domésticos com P\&D no Brasil mostra uma dissociação com a matriz tecnológica mundial. Comparativamente a outras economias, o Brasil apresenta baixos níveis de investimentos em P\&D. Em 2015 destinou 1,7 do produto interno bruto (PIB) a investimentos na área de inovaçáo tecnológica. Países da Uniấo Europeia, China, Coreia do Sul e Israel destinaram no mesmo ano 1,96, 2,06, 4,22 e 4,27, respectivamente, do PIB para atividades de P\&D (OECD, 2005).

$O$ financiamento à $P \& D$ nas empresas é um dos instrumentos universalmente mais utilizados como política de inovação e tem impacto positivo sobre a produtividade e crescimento das firmas. A promoção da inovaçấo tecnológica passou a ser incluída enfaticamente nos objetivos da política de desenvolvimento brasileira a partir do final dos anos 1990, com a promoção de profundas reformas políticas no âmbito do fomento à inovaçáo (MORAIS, 2008), a despeito da continuidade do papel das empresas como um agente externo em tais políticas.

Há no Brasil modalidades de fomento à inovação na forma de financiamentos reembolsáveis, não reembolsáveis e de incentivos fiscais. Os recursos reembolsáveis, segundo Coelho e De Negri (2011), têm o objetivo de alocar o crédito nos projetos em que os retornos sociais são mais altos, levando em conta os possíveis efeitos de transbordamento tecnológico para o restante da cadeia produtiva. Desse modo, o financiamento direto do governo permite que os subsídios públicos sejam direcionados para atividades que são pensadas para oferecer os mais altos retornos 
sociais dos gastos com pesquisa. A avaliação dos resultados dos projetos é difícil, tanto por causa da estimação dos benefícios sociais mais amplos gerados por eles, como pela necessidade de estabelecer o que teria sido contrafactual na ausência de financiamento público (JAUMOTTE; PAIN, 2005).

Já os incentivos fiscais à inovaçáo atendem a praticamente todos os tipos de empresa, reduzindo os custos com equidade, uma vez que conseguem atender a diferentes objetivos, tipos de firmas e setores industriais simultaneamente (AVELAR; ALVES, 2008). Entretanto, esses incentivos não adiantam recursos financeiros para as atividades tecnológicas, apenas reembolsam os gastos já realizados, excluindo assim empresas de pequeno porte que não possuem capital suficiente para os investimentos requeridos e não contemplando aquelas que poderiam se tornar inovadoras.

Para contornar esse tipo de viés, os recursos não reembolsáveis têm objetivo de compartilhar com perfis selecionados de empresas os custos e riscos inerentes a atividades de inovação (MORAIS, 2008). Além das subvenções econômicas operacionalizadas pela Finep, destacam-se as seguintes categorias de financiamento não reembolsáveis à inovação em âmbito nacional: Pappe Subvenção (Finep), Prime (Finep), Funtec (BNDES), Programa Rhae (CNPq) e o Programa SEBRAEtec (Sebrae) (BUENO; TORKOMIAN, 2014; FINEP, 2017).

Formalmente, subvenção econômica é um tipo de subsídio governamental em que recursos públicos são destinados a empresas públicas ou privadas. Não demanda contraprestação direta em bens ou serviços, o que a diferencia dos investimentos diretos governamentais e se destina exclusivamente a despesas de custeio. Os recursos da subvenção são provenientes dos fundos setoriais de ciência e tecnologia, criados entre 1997 e 2004, cujas receitas são direcionadas ao orçamento anual do Fundo Nacional de Ciência e Tecnologia (FNDCT) (MORAIS, 2012).

A parcela do projeto a ser subvencionada deve prever apenas despesas de custeio diretamente relacionadas à $\mathrm{P} \& \mathrm{D}$, estando a cargo das empresas proponentes todas as despesas de capital e outros custos envolvidos no projeto de inovação apresentado, na forma de contrapartida (FINEP, 2017).

Como as regras da aplicação das subvençóes pressupóem a intenção de induzir o investimento privado na geração de inovação, as subvençóes econômicas podem ser analisadas sob dois pontos de vista: o dos gastos do governo com a concessão desses recursos e o do investimento privado, que está sendo estimulado a aumentar. É esse o ponto que a aplicação de um novo modelo empírico de EGC, dotado da distinção entre capital físico e capital de conhecimento e capaz de analisar os efeitos dos gastos em P\&D sobre o sistema econômico, busca analisar: verificar se a concessão 
de subvençôes econômicas gera algum impacto sobre variáveis macroeconômicas e setoriais, por meio da indução do investimento privado em inovaçáo.

\section{Capital de conhecimento, produtividade e crescimento: evidências empíricas}

Os primeiros trabalhos utilizando modelos EGC com dados referentes à $\mathrm{P} \& \mathrm{D}$ e capital de conhecimento remontam à década de 1990 e objetivavam estudar os efeitos da inovação sobre a produtividade e analisar as políticas públicas de P\&D. Pioneiramente, Diao et al. (1996) propuseram um modelo baseado na teoria do crescimento endógeno incorporando dados referentes à $\mathrm{P} \& \mathrm{D}$. Refinando este, Kř́ístková (2012) buscou quantificar o impacto das atividades de P\&D sobre o crescimento econômico de longo prazo e Yeo et al. (2016) avançaram ao mensurar a influência da inovação sobre a economia em termos de crescimento e distribuição de renda, observando a estrutura de emprego.

Além dos efeitos sobre o crescimento econômico, a literatura mostra que, assim como os resultados advindos da P\&D doméstica, a absorção do conhecimento de outras fontes é decisiva para a produtividade e competitividade da economia (BYE; FAEHN; GRÜNFELD, 2011; ZÜRN et al., 2007; GHOSH, 2007). Também são encontradas evidências empíricas para os ganhos de produtividade ao estimular a geração de P\&D, como em Bye, Fæhn e Grünfeld (2011), cujo modelo busca analisar as inter-relaçóes entre $\mathrm{P} \& \mathrm{D}$, comércio e produtividade.

Para examinar os diversos efeitos das políticas de incentivo à inovação, modelos de EGC dinâmicos, que modelam a acumulaçâo de capital temporalmente de acordo com os investimentos em P\&D, têm se mostrado úteis e adequados (GARAU; LECCA, 2008; BOR et al., 2010; BYE, FÆHN E HEGGEDAL, 2009; VISSER, 2007; ZAWALIŃSKA, TRAN; PŁOSZAJ, 2016; HONG et al., 2016). Metodologicamente, a maioria dos estudos implementou modelos de EGC tratando o capital de conhecimento como um dos fatores primários (Quadro 1), de modo que as mudanças tecnológicas contribuam para a explicação das alterações no comportamento da economia mais adequadamente (GHOSH, 2007; HONG et al., 2016).

Para isso, Diao et al. (1996) fizeram com que os valores de capital se dividissem em capital físico e capital de conhecimento, para que este pudesse ser o insumo de produção do setor de P\&D, assim como Ghosh (2007) e Kř́stková (2012) também o fizeram. Similarmente, Visser (2007) inclui o capital gerado pela P\&D como fator de produção. No modelo, a P\&D é modelada como uma variável de estoque com taxa 


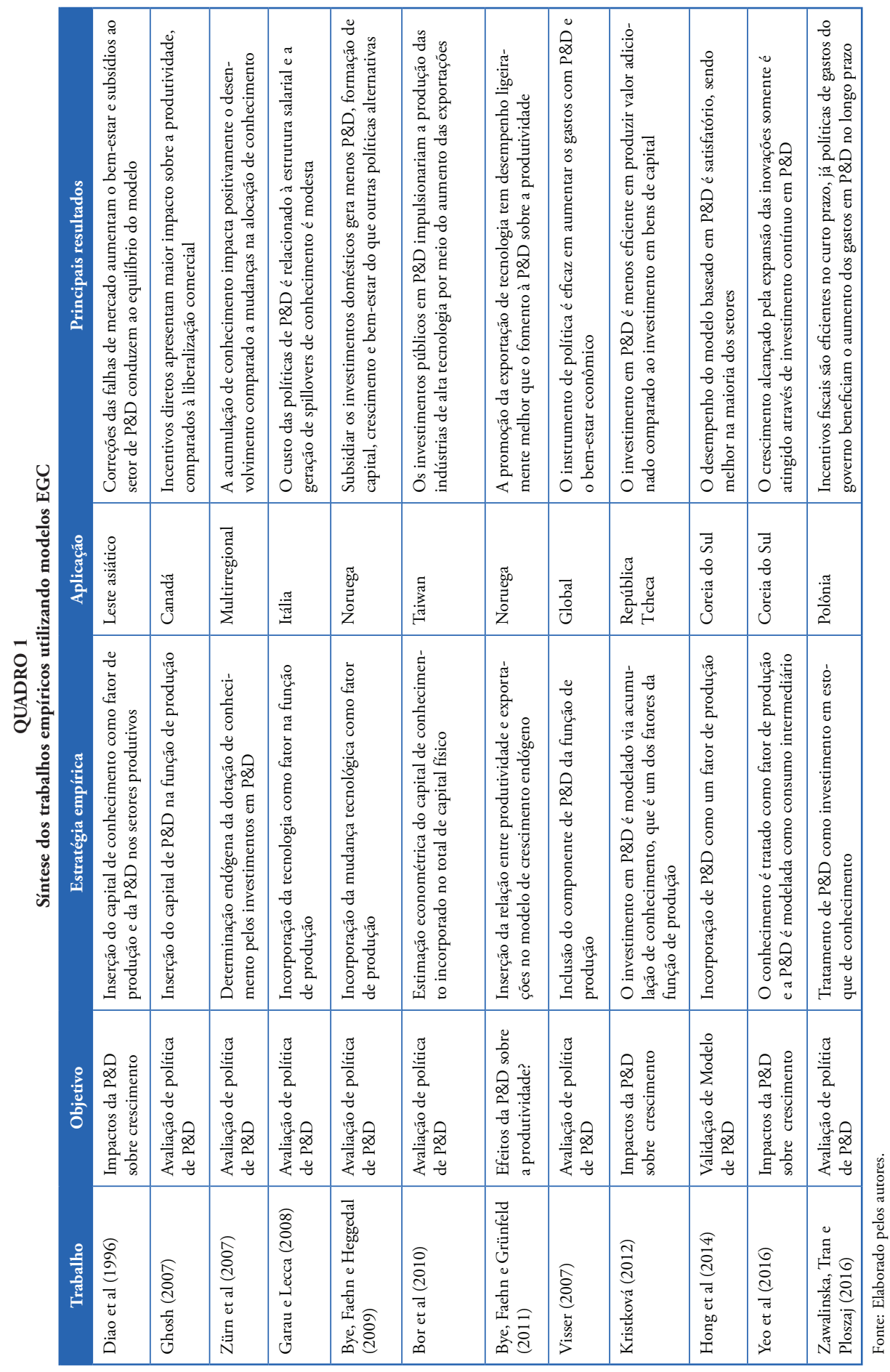


constante de depreciação. A construção do estoque de $P \& D^{1}$ é análoga à construção do estoque de capital físico e, assim, os gastos em P\&D podem ser interpretados como investimentos, cujos efeitos se propagam no tempo. Outros trabalhos que alteram a função de produção do modelo são o de Garau e Lecca (2008), de Zürn et al. (2007) e o de Bye, Fæhn e Heggedal (2009), cujas calibraçôes incluem um fator intangível na função de produção. Bor et al. (2010) diferem destes últimos por usarem métodos econométricos para estimar o capital de conhecimento incorporado no capital físico. Já Hong et al. (2016) modelam o conhecimento como um fator de produçáo e o capital de conhecimento alheio é considerado uma fonte de transbordamentos de produtividade total dos fatores.

A revisão dos trabalhos utilizando modelos de equilíbrio geral dinâmicos mostra que a construção do modelo BIM-KC o torna apto a discutir como as subvençôes à inovação podem impactar os setores produtivos e aumentar o estoque de capital de conhecimento, gerando maior probabilidade de crescimento econômico via inovaçóes tecnológicas para a economia brasileira.

\section{0 modelo BIM-KC}

O modelo BIM-KC (Brazilian Intersectoral Model - knowledge capital) é uma versão recursiva que estende a especificação do modelo ORANIRD de Horridge, Parmenter e Pearson (2000). O modelo BIM-KC discrimina a relação fluxo-estoque de capital de conhecimento e capital físico, cuja estrutura teórica representa um avanço em relação aos modelos tradicionais de EGC. Ou seja, há uma nova especificação de acumulaçáo de capital de conhecimento ao longo do tempo, que responde positivamente à alocação dos investimentos de $\mathrm{P} \& \mathrm{D}$ por setor produtivo, como tradicionalmente modelado por um método do inventário perpétuo:

$$
K_{j, i, t}=\left(1-d_{j, i}\right) K_{j, i, t-1}+I_{j, i, t} \forall j=\left(K_{F}, K_{C}\right)
$$

em que $K_{F}$ é o estoque de capital físico, $K_{C}$ é o estoque de capital de conhecimento, $d$ é a taxa de depreciação e $I$ é o investimento. A evolução do estoque de capital depende do quanto é investido na economia e da taxa de depreciação do capital $\left(d_{j, i}\right)$, definida como invariante no tempo. O BIM-KC assume que o insumo de P\&D é utilizado exclusivamente para formar uma unidade a mais de capital de co-

1 Esse método de construção do estoque de capital de conhecimento é denominado método do inventário perpétuo. 
nhecimento, o mesmo ocorrendo para o capital físico. Desse modo, presume-se que há um efeito de complementariedade entre o capital de conhecimento e o capital físico, enquanto insumos produtivos especificados no modelo.

A especificação do comportamento dos investimentos é feita em estado de fluxo, dependendo das flutuaçóes da taxa bruta esperada de retorno em relação à tendência da economia ao longo do tempo. A alocação dos investimentos acompanha a lógica Q de Tobin por uma função logística. De acordo com Horridge (2006), a alocação de investimentos é definida por duas regras básicas (CHEN, 2019):

$$
\begin{gathered}
G_{i}=\frac{I_{i, t}}{K_{i, t}}=F\left(E_{i}\right) \\
G_{i}=Q_{i} \cdot G_{i}^{T e n d} \cdot \frac{\left(M_{i}\right)^{\xi_{i}}}{Q_{i}-1+\left(M_{i}\right)^{\xi_{i}}}
\end{gathered}
$$

de maneira que na eq. (2) a razão investimento/capital ou taxa bruta de crescimento de capital no próximo período estão positivamente relacionados com as taxas de retorno esperadas $\left(E_{i}\right)$; e na eq. (3) as taxas de retorno esperadas convergem para as taxas de retorno reais por meio de um mecanismo de ajuste parcial (CHEN, 2019), com $M_{i}=E_{i} / R_{i}^{\text {Normal }}$, tal que $R_{j, i}^{\text {Normal }}$ é a taxa de retorno normal do capital para o investidor i; $G_{i}^{\text {Tend }}$ é a tendência de crescimento dos estoques de capital, $Q_{j i}$ é a relação investimento/capital (máxima/tendência); e $\xi_{i}$ denota a elasticidade do investimento.

Em conformidade com uma estrutura EGC padrão, produtores e investidores minimizam os custos para o nível de produçáo e criação de capital (DIXON, 1982). A demanda dos compostos de insumos ocorre em proporçôes fixas (Leontief). Entretanto, cada composto de insumo é derivado de uma função de elasticidade de substituição constante (CES) (ARMINGTON, 1969). Por seu turno, as famílias maximizam a utilidade a partir de um sistema linear de despesas (LES) (KLEIN; RUBIN, 1947) sujeita a uma restrição orçamentária., enquanto a demanda externa muda inversamente ao preço médio em moeda estrangeira das exportaçóes, sendo a taxa de câmbio exógena (numerário). Além disso, o consumo do governo é exógeno e os estoques se acumulam de acordo com a variação da produção.

O modelo foi calibrado para os dados das contas nacionais e da matriz de insumo-produto do Instituto Brasileiro de Geografia e Estatística (IBGE) do ano de 2010. Ele reconhece 67 setores que produzem um ou mais dos 127 produtos, 
utilizando insumos domésticos e importados, e quatro fatores primários (trabalho, terra, capital físico e capital de conhecimento). Existem, pois, cinco tipos de usuários finais: investidores, famílias, governo, consumidor estrangeiro (exportaçóes) e variaçóes de estoques.

No processo de calibragem do modelo, os valores de estoque de capital de conhecimento foram obtidos por uma dedução algébrica a partir da eq. (1):

$$
\frac{I}{K C}=\left[\left(\frac{K C_{t}}{K}\right)-1\right]+d
$$

Para o cálculo foram utilizados os valores de produção não mercantil do produto "Pesquisa e Desenvolvimento", que é destinado à FBCF como o investimento em capital de conhecimento $(K C)$. Para o cálculo do estoque de capital de conhecimento, bastou dividir o investimento em capital de conhecimento pela taxa de crescimento bruta da economia, estipulada a 5 . Desse modo, com essas hipóteses sustentadas pela literatura da área (e.g.: HALL, 1993; GRILICHES, 1991; LOS; VERSPAGEN, 2000; NADIRI; PRUCHA, 1996), obteve-se a série de estoque de capital de conhecimento para os setores produtivos da economia a partir dos dados disponibilizados pelo IBGE.

Para a calibragem da remuneração do capital de conhecimento, tem-se que esta é o produto do estoque de capital de conhecimento e da taxa de retorno desse capital, estipulada arbitrariamente pela literatura empírica em 20 (CBO, 2005). É estabelecido que as estimativas da taxa de retorno de P\&D variam muito, encontrando-se no intervalo de estimativas da taxa de retorno do investimento em $P \& D$ de zero a quase 0,60 , com uma tendência central entre 0,20 e 0,30. A ampla variação nas estimativas provavelmente deve-se à diferença entre os estudos nos dados utilizados ou na especificação da equaçáo da produtividade total dos fatores (CBO, 2005; WOLFF, 1997). Portanto, adotou-se para esta calibragem o limite inferior da tendência central porque, no Brasil, a natureza adaptativa do processo inovativo é refletida na baixa capacidade de inovar, sendo uma hipótese razoável supor que o retorno dessas atividades seja baixo.

\subsection{Análise de política}

Para operacionalizar as simulaçóes de política no modelo BIM-KC entre os anos de 2010 e 2030, primeiro é preciso determinar o baseline do modelo - que se constitui num cenário macroeconômico que reproduz as variaçóes dos principais 
componentes da demanda final observados até o ano de 2017 e projetados entre 2018 até 2030. O baseline configura-se num cenário tendencial da economia, cujos desvios em relação a ele podem ser mensurados, projetando efeitos de choques de políticas sugeridas. Para isso, foram utilizados dados referentes ao PIB, investimento, consumo das famílias, gastos do governo e exportaçóes no período de 2011 a 2030. As trajetórias prospectivas são incorporadas como choques no modelo EGC, que calcula endogenamente o cenário completo para a economia brasileira até o ano de 2030. As estimativas para as taxas de variação anual do PIB, investimento, consumo das famílias, consumo do Governo e exportaçóes do relatório de inflação do Banco Central são resultados de pesquisa do BNDES (HORTA; GIAMBIAGI, 2018), com a vantagem de que estes levam em consideração o crescimento dos componentes da demanda final, cujo crescimento é consistente com o crescimento do PIB. Entre os anos de 2018 e 2030, são consideradas taxas de crescimento estimadas para a economia brasileira de 2. Para o consumo das famílias, estima-se crescimento de 1,5 e para os gastos do governo, 0,7. Já para o investimento agregado da economia e das exportaçóes, são previstas taxas de crescimento de 1,7 e 4,6, respectivamente.

A partir do cenário de referência (baseline), estabelece-se o choque no fechamento de política, ou seja, os cortes nos valores observados das concessōes de subvençóes entre 2010 e 2016, dados estes obtidos junto à Finep por meio de requisição formal amparada pela Lei de Acesso à Informação (Lei no 12527/2011). ${ }^{2}$ Uma simulaçáo de política permite analisar os efeitos de uma mudança na política econômica, sendo ela um desvio das variáveis econômicas em relação ao cenário de referência. Essa diferença pode ser interpretada como os efeitos da mudança de política (DIXON; RIMMER, 2002).

A Tabela 1 reporta o total dispendido com as concessões das subvençôes econômicas durante o período para cada um dos setores, cujos valores são utilizados como referência para os choques de política. Dentre as atividades setoriais destacam-se os setores de Fabricação de máquinas e equipamentos elétricos; Intermediação financeira, seguros e previdência complementar; Serviços de arquitetura, engenharia, testes/análises técnicas e P\&D; e Fabricação de produtos farmoquímicos e farmacêuticos. Esses setores produtivos receberam a maior quantidade de recursos do programa de subvenção e foram os mais presentes nos anos de concessão. Observa-se também, contudo, a presença de atividades e serviços não industriais. No caso do setor denominado de "Outras atividades administrativas e serviços complementares",

2 Os valores e demais dados das subvençóes econômicas foram obtidos através de solicitação ao Portal de Acesso à Informação do Governo Federal, o e-SIC (http://www.acessoainformacao.gov.br/sistema/). 
encontram-se classificadas empresas de desenvolvimento de softwares por exemplo. Essas empresas têm por definição a busca constante por inovação e aprimoramento tecnológico, estando muitas vezes na fronteira do desenvolvimento tecnológico entre os setores produtivos e por essa razão constitui-se um setor de destaque no recebimento dos recursos de subvenção à inovaçáo.

TABELA 1

Soma dos valores concedidos de subvenção econômica período 2010 - 2016 (valores correntes)

\begin{tabular}{|c|c|c|c|}
\hline Código & Siglas & Descriçáo do setor & $\begin{array}{l}\text { Valores recebidos } \\
\text { (em R\$ milhóes) }\end{array}$ \\
\hline 1 & AgricultOut & $\begin{array}{l}\text { Agricultura, inclusive o apoio à agricultura e a } \\
\text { pós-colheita }\end{array}$ & 0,50 \\
\hline 2 & Pecuria & Pecuária, inclusive o apoio à pecuária & 0,00 \\
\hline 3 & FlorPescAq & Produção florestal; pesca e aquicultura & 0,00 \\
\hline 4 & CarvaoMNMet & $\begin{array}{l}\text { Extração de carvão mineral e de minerais não- } \\
\text {-metálicos }\end{array}$ & 0,00 \\
\hline 5 & PetrolGas & $\begin{array}{l}\text { Extraçáo de petróleo e gás, inclusive as atividades } \\
\text { de apoio }\end{array}$ & 2,50 \\
\hline 6 & MinerioFerr & $\begin{array}{l}\text { Extração de minério de ferro, inclusive beneficia- } \\
\text { mentos e a aglomeração }\end{array}$ & 0,00 \\
\hline 7 & MMNFerro & $\begin{array}{l}\text { Extração de minerais metálicos não-ferrosos, } \\
\text { inclusive beneficiamentos }\end{array}$ & 0,00 \\
\hline 8 & AbateCarne & $\begin{array}{l}\text { Abate e produtos de carne, inclusive os produtos } \\
\text { do laticínio e da pesca }\end{array}$ & 0,00 \\
\hline 9 & RefAcucar & Fabricação e refino de açúcar & 0,00 \\
\hline 10 & OtPAliment & Outros produtos alimentares & 20,04 \\
\hline 11 & Bebidas & Fabricação de bebidas & 0,00 \\
\hline 12 & PFumo & Fabricação de produtos do fumo & 21,57 \\
\hline 13 & PTexteis & Fabricação de produtos têxteis & 0,00 \\
\hline 14 & AVestuario & Confecção de artefatos do vestuário e acessórios & 0,00 \\
\hline 15 & CalcCouro & Fabricação de calçados e de artefatos de couro & 0,00 \\
\hline 16 & PdMadeira & Fabricação de produtos da madeira & 4,70 \\
\hline 17 & CelulPapel & Fabricação de celulose, papel e produtos de papel & 5,48 \\
\hline 18 & ImpressRep & Impressão e reprodução de gravaçóes & 8,13 \\
\hline 19 & RfPetrol & Refino de petróleo e coquerias & 0,00 \\
\hline 20 & Biocomb & Fabricação de biocombustíveis & 0,00 \\
\hline 21 & PQuimicos & $\begin{array}{l}\text { Fabricação de químicos orgânicos e inorgânicos, } \\
\text { resinas e elastômeros }\end{array}$ & 69,74 \\
\hline
\end{tabular}


TABELA 1

Soma dos valores concedidos de subvençáo econômica período 2010 - 2016 (valores correntes)

\begin{tabular}{|c|c|c|c|}
\hline Código & Siglas & Descrição do setor & $\begin{array}{l}\text { Valores recebidos } \\
\text { (em R } \$ \text { milhóes) }\end{array}$ \\
\hline 22 & DefAgric & $\begin{array}{l}\text { Fabricação de defensivos, desinfestantes, tintas e } \\
\text { químicos diversos }\end{array}$ & 4,24 \\
\hline 23 & Perfuma & $\begin{array}{l}\text { Fabricação de produtos de limpeza, cosméticos/ } \\
\text { perfumaria e higiene pessoal }\end{array}$ & 7,15 \\
\hline 24 & Farmac & $\begin{array}{l}\text { Fabricação de produtos farmoquímicos e farma- } \\
\text { cêuticos }\end{array}$ & 92,24 \\
\hline 25 & BorraPlast & $\begin{array}{l}\text { Fabricação de produtos de borracha e de material } \\
\text { plástico }\end{array}$ & 22,30 \\
\hline 26 & PMNMeta & Fabricação de produtos de minerais não-metálicos & 6,93 \\
\hline 27 & FAcoDeriv & $\begin{array}{l}\text { Produçáo de ferro-gusa/ferroligas, siderurgia e } \\
\text { tubos de aço sem costura }\end{array}$ & 5,16 \\
\hline 28 & MetNFerros & $\begin{array}{l}\text { Metalurgia de metais não-ferosos e a fundição de } \\
\text { metais }\end{array}$ & 2,03 \\
\hline 29 & PMetal & $\begin{array}{l}\text { Fabricação de produtos de metal, exceto máqui- } \\
\text { nas e equipamentos }\end{array}$ & 57,01 \\
\hline 30 & EscInformat & $\begin{array}{l}\text { Fabricação de equipamentos de informática, } \\
\text { produtos eletrônicos e ópticos }\end{array}$ & 36,34 \\
\hline 31 & MqEletrico & Fabricação de máquinas e equipamentos elétricos & 172,18 \\
\hline 32 & MaqEquip & $\begin{array}{l}\text { Fabricação de máquinas e equipamentos mecâ- } \\
\text { nicos }\end{array}$ & 0,00 \\
\hline 33 & AutomUtil & $\begin{array}{l}\text { Fabricação de automóveis, caminhôes e ônibus, } \\
\text { exceto peças }\end{array}$ & 0,00 \\
\hline 34 & PecVeicAut & $\begin{array}{l}\text { Fabricaçáo de peças e acessórios para veículos } \\
\text { automotores }\end{array}$ & 11,49 \\
\hline 35 & OtEqTransp & $\begin{array}{l}\text { Fabricação de outros equipamentos de transporte, } \\
\text { exceto veículos automotores }\end{array}$ & 67,98 \\
\hline 36 & IndDiversas & $\begin{array}{l}\text { Fabricação de móveis e de produtos de indústrias } \\
\text { diversas }\end{array}$ & 37,78 \\
\hline 37 & ManRepMqEq & $\begin{array}{l}\text { Manutenção, reparação e instalação de máquinas } \\
\text { e equipamentos }\end{array}$ & 56,08 \\
\hline 38 & EletriGasUt & Energia elétrica, gás natural e outras utilidades & 0,70 \\
\hline 39 & AguaEsgosto & Água, esgoto e gestão de resíduos & 0,00 \\
\hline 40 & Construção & Construção & 18,00 \\
\hline 41 & Comércio & Comércio por atacado e varejo & 62,48 \\
\hline 42 & Terrestre & Transporte terrestre & 0,00 \\
\hline 43 & Aquaviário & Transporte aquaviário & 0,00 \\
\hline 44 & Aereo & Transporte aéreo & 0,00 \\
\hline
\end{tabular}


TABELA 1

Soma dos valores concedidos de subvençáo econômica período 2010 - 2016 (valores correntes)

\begin{tabular}{|c|c|c|c|}
\hline Código & Siglas & Descriçáo do setor & $\begin{array}{l}\text { Valores recebidos } \\
\text { (em R\$ milhóes) }\end{array}$ \\
\hline 45 & ArmAuxTr & $\begin{array}{l}\text { Armazenamento, atividades auxiliares dos trans- } \\
\text { portes e correio }\end{array}$ & 11,97 \\
\hline 46 & AlojHoteis & Alojamento & 0,00 \\
\hline 47 & ServAlim & Alimentação & 0,00 \\
\hline 48 & EdicaoImp & Edição e edição integrada à impressão & 0,00 \\
\hline 49 & TvRadioCine & $\begin{array}{l}\text { Atividades de televisão, rádio, cinema e gravação/ } \\
\text { ediçáo de som e imagem }\end{array}$ & 23,67 \\
\hline 50 & Telecom & Telecomunicações & 0,00 \\
\hline 51 & DenSistema & $\begin{array}{l}\text { Desenvolvimento de sistemas e outros serviços de } \\
\text { informaçáo }\end{array}$ & 0,00 \\
\hline 52 & InFinanSeg & $\begin{array}{l}\text { Intermediaçáo financeira, seguros e previdência } \\
\text { complementar }\end{array}$ & 110,63 \\
\hline 53 & AlugImobi & Atividades imobiliárias & 0,00 \\
\hline 54 & JuridCont & $\begin{array}{l}\text { Atividades jurídicas, contábeis, consultoria e } \\
\text { sedes de empresas }\end{array}$ & 81,11 \\
\hline 55 & ArquitEngen & $\begin{array}{l}\text { Serviços de arquitetura, engenharia, testes/análi- } \\
\text { ses técnicas e } P \& D\end{array}$ & 103,25 \\
\hline 56 & OtAtTecnCien & $\begin{array}{l}\text { Outras atividades profissionais, científicas e téc- } \\
\text { nicas }\end{array}$ & 0,00 \\
\hline 57 & AlugueisNImo & $\begin{array}{l}\text { Aluguéis náo-imobiliários e gestấo de ativos de } \\
\text { propriedade intelectual }\end{array}$ & 0,00 \\
\hline 58 & OtAdmin & $\begin{array}{l}\text { Outras atividades administrativas e serviços com- } \\
\text { plementares }\end{array}$ & 152,90 \\
\hline 59 & VigSegur & Atividades de vigilância, segurança e investigação & 0,00 \\
\hline 60 & AdmPubSegS & Administração pública, defesa e seguridade social & 3,68 \\
\hline 61 & EducPublic & Educação pública & 0,00 \\
\hline 62 & EducPriv & Educação privada & 0,00 \\
\hline 63 & SaudePublic & Saúde pública & 0,00 \\
\hline 64 & SaudePriv & Saúde privada & 7,53 \\
\hline 65 & ArtesCultE & Atividades artísticas, criativas e de espetáculos & 0,00 \\
\hline 66 & OrgAssocia & Organizações associativas e outros serviços pessoais & 0,00 \\
\hline 67 & SvDomestic & Serviços domésticos & 0,00 \\
\hline
\end{tabular}

Fonte: Elaborada pelos autores.

Esses valores foram aplicados ao modelo ano a ano, de acordo com a data de início do contrato entre as empresas e a Finep e, uma vez que o modelo é dinâmico, 
tais valores alimentaram os choques aplicados anualmente. Os valores são referentes a cada um dos projetos subvencionados, identificados por empresa proponente e agregados pela Classificação Nacional das Atividades Econômicas (CNAE 2.0) do IBGE. Após compatibilização, obteve-se o montante de recursos concedidos por setores produtivos do SCN do IBGE em cada um dos anos do período de concessão observado (Tabela 2).

TABELA 2

Valores calculados para o choque na concessão de subvençóes (valores correntes)

\begin{tabular}{|c|c|c|c|c|c|c|c|c|}
\hline \multirow[b]{2}{*}{ Setores } & \multicolumn{8}{|c|}{ Variação monetária anual (em milhóes de $\mathbf{R} \$$ ) } \\
\hline & 2010 & 2011 & 2012 & 2013 & 2014 & 2015 & 2016 & $\begin{array}{r}\text { Porcenta- } \\
\text { gem das } \\
\text { subven- } \\
\text { çóes em } \\
\text { relaçáo ao } \\
\text { VBP } 0\end{array}$ \\
\hline $\begin{array}{l}\text { Agricultura, inclusive o apoio } \\
\text { à agricultura e a pós-colheita }\end{array}$ & & & 0,50 & & & & & 0,07 \\
\hline $\begin{array}{l}\text { Extraçáo de petróleo e gás, in- } \\
\text { clusive as atividades de apoio }\end{array}$ & & & & & 2,50 & & & 0,47 \\
\hline Outros produtos alimentares & 2,66 & 2,64 & 4,06 & 2,05 & & 8,63 & & 1,58 \\
\hline Fabricação de produtos do fumo & 21,57 & & & & & & & 21,99 \\
\hline $\begin{array}{l}\text { Fabricação de produtos da ma- } \\
\text { deira }\end{array}$ & & 1,20 & & & 3,50 & & & 3,77 \\
\hline $\begin{array}{l}\text { Fabricaçấo de celulose, papel e } \\
\text { produtos de papel }\end{array}$ & 2,64 & & & 2,84 & & & & 1,34 \\
\hline $\begin{array}{l}\text { Impressão e reprodução de } \\
\text { gravaçóes }\end{array}$ & 8,13 & & & & & & & 8,29 \\
\hline $\begin{array}{l}\text { Fabricação de químicos orgâ- } \\
\text { nicos e inorgânicos, resinas e } \\
\text { elastômeros }\end{array}$ & 22,25 & 3,70 & & 24,97 & 14,30 & 4,52 & & 9,36 \\
\hline $\begin{array}{l}\text { Fabricação de defensivos, de- } \\
\text { sinfestantes, tintas e químicos } \\
\text { diversos }\end{array}$ & & 2,41 & & 0,76 & 1,08 & & & 1,12 \\
\hline $\begin{array}{l}\text { Fabricação de produtos de lim- } \\
\text { peza, cosméticos/perfumaria e } \\
\text { higiene pessoal }\end{array}$ & 0,50 & & & & 6,65 & & & 3,67 \\
\hline $\begin{array}{l}\text { Fabricação de produtos farmo- } \\
\text { químicos e farmacêuticos }\end{array}$ & 5,82 & 8,12 & 15,68 & 0,99 & 39,28 & 22,35 & & 43,41 \\
\hline $\begin{array}{l}\text { Fabricaçấo de produtos de bor- } \\
\text { racha e de material plástico }\end{array}$ & 2,39 & 4,96 & 2,89 & 3,58 & 6,21 & 2,29 & & 4,35 \\
\hline $\begin{array}{l}\text { Fabricação de produtos de mi- } \\
\text { nerais não-metálicos }\end{array}$ & 3,52 & & 1,69 & & & 1,72 & & 1,66 \\
\hline $\begin{array}{l}\text { Produção de ferro-gusa/ferro- } \\
\text { ligas, siderurgia e tubos de aço } \\
\text { sem costura }\end{array}$ & 5,16 & & & & & & & 0,69 \\
\hline
\end{tabular}


TABELA 2

Valores calculados para o choque na concessáo de subvençóes (valores correntes)

\begin{tabular}{|c|c|c|c|c|c|c|c|c|}
\hline \multirow[b]{2}{*}{ Setores } & \multicolumn{8}{|c|}{ Variaçáo monetária anual (em milhóes de $\mathrm{R} \$$ ) } \\
\hline & 2010 & 2011 & 2012 & 2013 & 2014 & 2015 & 2016 & $\begin{array}{r}\text { Porcenta- } \\
\text { gem das } \\
\text { subven- } \\
\text { çóes em } \\
\text { relaçáo ao } \\
\text { VBP } 0\end{array}$ \\
\hline $\begin{array}{l}\text { Fabricação de produtos de me- } \\
\text { tal, exceto máquinas e equi- } \\
\text { pamentos }\end{array}$ & 37,87 & 1,28 & & 0,78 & 17,08 & & & 12,26 \\
\hline $\begin{array}{l}\text { Fabricação de equipamentos de } \\
\text { informática, produtos eletrôni- } \\
\text { cos e ópticos }\end{array}$ & 22,02 & 1,38 & 0,88 & & 10,33 & 1,72 & & 7,20 \\
\hline $\begin{array}{l}\text { Fabricação de máquinas e equi- } \\
\text { pamentos elétricos }\end{array}$ & 46,18 & 84,85 & 1,78 & 1,65 & 22,96 & 14,76 & & 39,15 \\
\hline $\begin{array}{l}\text { Fabricação de peças e acessórios } \\
\text { para veículos automotores }\end{array}$ & 1,24 & & & 1,00 & 0,00 & 5,14 & 4,12 & 2,02 \\
\hline $\begin{array}{l}\text { Fabricação de outros equipa- } \\
\text { mentos de transporte, exceto } \\
\text { veículos automotores }\end{array}$ & 40,76 & 0,50 & & 7,78 & 16,50 & 2,44 & & 28,97 \\
\hline $\begin{array}{l}\text { Fabricação de móveis e de pro- } \\
\text { dutos de indústrias diversas }\end{array}$ & 8,05 & 5,08 & 8,06 & & 10,15 & 6,44 & & 13,94 \\
\hline $\begin{array}{l}\text { Manutenção, reparação e ins- } \\
\text { talaçáo de máquinas e equi- } \\
\text { pamentos }\end{array}$ & 32,76 & 7,08 & 3,81 & & 6,03 & 6,40 & & 22,31 \\
\hline $\begin{array}{l}\text { Energia elétrica, gás natural e } \\
\text { outras utilidades }\end{array}$ & & & & & 0,70 & & & 0,08 \\
\hline Construção & 4,01 & 5,75 & 1,12 & 5,49 & 1,64 & & & 0,75 \\
\hline Comércio & 26,34 & 15,41 & 5,02 & 3,23 & 10,38 & & 2,09 & 2,71 \\
\hline $\begin{array}{l}\text { Armazenamento, atividades au- } \\
\text { xiliares dos transportes e correio }\end{array}$ & & & 1,21 & & 10,76 & & & 4,15 \\
\hline $\begin{array}{l}\text { Atividades de televisão, rádio, } \\
\text { cinema e gravaçáo/ediçấo de } \\
\text { som e imagem }\end{array}$ & 23,67 & & & & & & & 14,91 \\
\hline $\begin{array}{l}\text { Intermediaçấo financeira, segu- } \\
\text { ros e previdência complementar }\end{array}$ & 79,84 & & 3,38 & 8,31 & 19,09 & & & 8,01 \\
\hline $\begin{array}{l}\text { Atividades jurídicas, contábeis, } \\
\text { consultoria e sedes de empresas }\end{array}$ & 47,15 & 16,28 & 1,00 & 7,06 & 9,63 & & & 22,35 \\
\hline $\begin{array}{l}\text { Serviços de arquitetura, enge- } \\
\text { nharia, testes/análises técnicas } \\
\text { e P\&D }\end{array}$ & 1,55 & 14,42 & 2,91 & 39,81 & 24,52 & 20,03 & & 61,24 \\
\hline $\begin{array}{l}\text { Outras atividades administrati- } \\
\text { vas e serviços complementares }\end{array}$ & 85,18 & 13,98 & 7,76 & 9,71 & 18,54 & 17,73 & & 39,19 \\
\hline $\begin{array}{l}\text { Administraçấo pública, defesa e } \\
\text { seguridade social }\end{array}$ & & & & & & & 3,68 & 0,26 \\
\hline Saúde privada & 6,71 & & 0,82 & & & & & 1,44 \\
\hline
\end{tabular}

Fonte:: Elaborada pela autora com base nos dados recebidos da Finep. 


\section{Resultados}

Para melhor visualizar o caminho de propagação do choque simulado, a Figura 1 exibe os principais mecanismos de transmissão dos efeitos da simulação da política. Nela, pode-se ver que o corte nos recursos de subvençáo econômica gera um conjunto de impactos negativos na economia derivados do comportamento otimizador dos agentes econômicos.

FIGURA 1

Principais relaçốes causais decorrentes da simulaçáo do choque

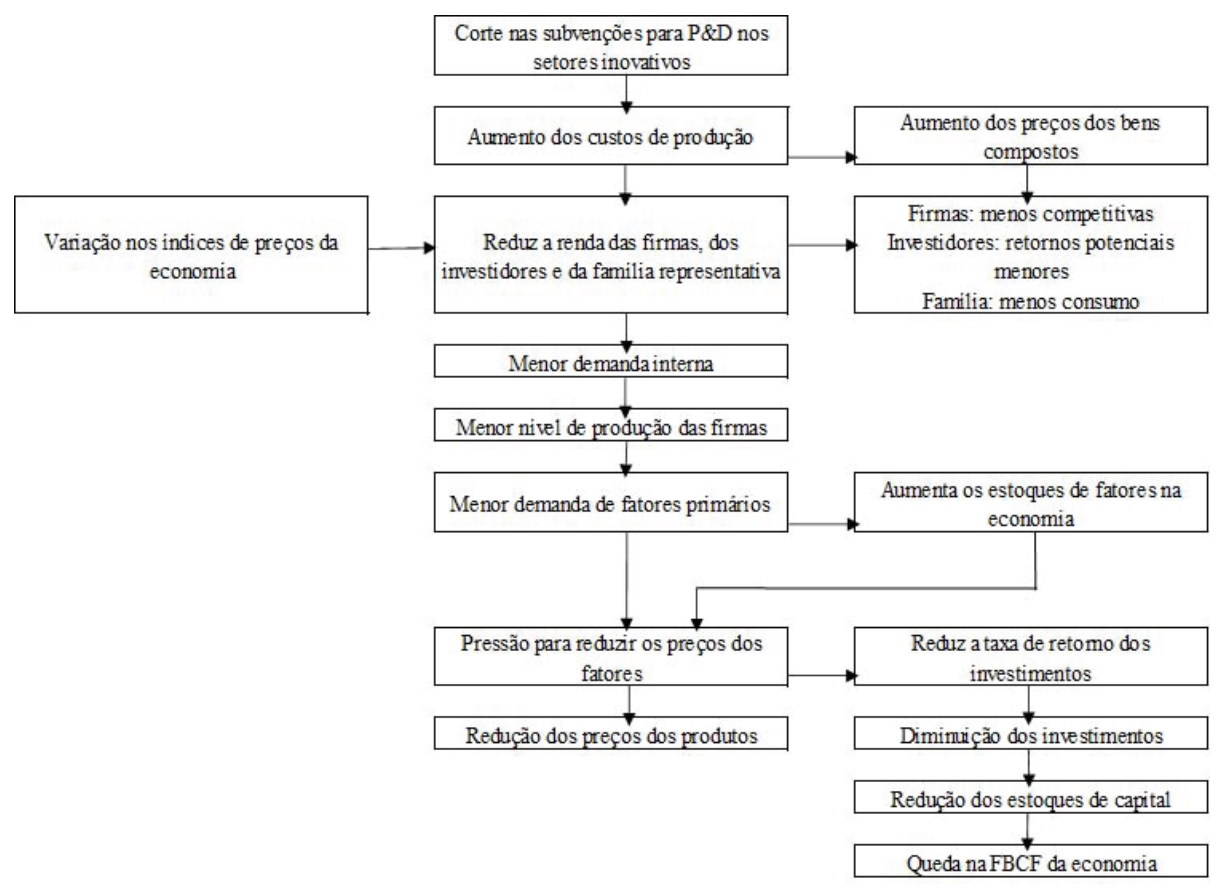

Fonte: Elaborado pela autora

Pelo lado da demanda, o corte nos recursos concedidos é percebido pelos setores que o recebiam como um aumento de custo de produção dos bens intermediários e de consumo final, o que gera um acréscimo dos preços dos bens compostos. Assim, restringe-se a competitividade das firmas dos setores diretamente atingidos pela política simulada, reduzindo a taxa de retorno dos investimentos devido à queda da rentabilidade do capital, aumentando os custos de produção dos bens e diminuindo a renda da família representativa. Dessa forma, há um encolhimento na renda dos agentes econômicos: produtores, investidores e consumidores - o que, 
por sua vez, irá atingir a demanda interna por meio da perda real de renda dos agentes. Em outras palavras, como a taxa de retorno do investimento náo se reduz em virtude do aumento dos custos de produçáo, mas sim pela queda da rentabilidade do capital, esse fator primário passa a ser menos requisitado na economia, em virtude da retração da atividade econômica. Destarte, há uma pressão de baixa do preço do capital na economia e, consequentemente, reduz-se a taxa de retorno esperada dos investimentos, válido tanto para o capital físico quanto para o capital de conhecimento. Com isso, haverá uma queda no nível de atividade produtiva das firmas, diminuindo a necessidade de uso dos fatores primários da economia que, por serem menos demandados, terão seus preços reduzidos. Isso faz com que haja uma redução dos preços dos produtos devido à pressão para a diminuição dos custos de produção.

A ausência das concessões dos recursos de subvenção faz com que os setores demandem menos fatores primários, incluindo o insumo capital de conhecimento. Portanto, pelo lado da oferta, há uma redução da disponibilidade de produção, dada a percepção de que a demanda a ser atendida foi reduzida. A queda na atividade produtiva dos setores causa a liberação dos insumos trabalho e capital físico, formando um excedente ocioso no mercado de fatores primários - o que pressiona a redução da remuneração dos mesmos. Essa redução nos custos de produção induz a uma queda dos preços dos produtos, tornando assim a produção doméstica mais competitiva.

Na Figura 1, o último efeito esboçado é o de redução dos preços dos produtos, que dá origem a uma percepçáo por parte dos agentes de que houve um aumento na renda e, assim, iniciar-se-á outro ciclo de impactos sobre a economia. Como efeitos secundários, tem-se que o aumento da demanda nos mercados de fatores e nos mercados de bens ocorre pelas vias da expansão da renda dos agentes ou pela elevação do nível de competitividade dos setores produtivos. Isso promoverá uma pressão de aumento no nível de preços. Deve-se considerar que cada um dos setores do modelo possui uma distribuição distinta do valor adicionado entre a remuneração do trabalho e capital, o que afeta a forma pela qual a renda gerada em cada setor será alocada no consumo de novos produtos.A Tabela 3 reporta as projeçóes macroeconômicas e setoriais do corte das subvençóes econômicas da Finep. Com o corte nos subsídios, esperava-se a imediata verificação do aumento dos custos de produção dos setores, o que geraria uma queda da produção. Pela transmissão dos efeitos, verificou-se uma retração da produção dos setores diretamente beneficiados pelas subvençóes, pois os custos de insumos por unidade de produto ficaram mais 
caros. Esse resultado ocorreu sobretudo naquelas atividades intensivas em capital físico e de conhecimento.

Os impactos são pequenos e eles reproduzem a magnitude da concessão do fomento em relação à produção nacional. Apesar disso, os efeitos são desproporcionais entre os setores porque levam em conta os canais diretos e indiretos dos vínculos de produção e consumo em um sistema de equilíbrio geral. Para melhor demonstração dos resultados, estes foram separados em efeitos macroeconômicos e setoriais.

\subsection{Efeitos macroeconômicos}

Minimizadores de custos, os setores produtivos ajustam as dotaçóes de insumos e fatores conforme a produção. Diante da retração produtiva, fatores primários foram liberados, levando à queda dos salários e rentabilidade do capital. Esta, por sua vez, afetou negativamente a taxa de retorno esperada e, por conseguinte, a demanda de investimentos na economia. Como os investidores utilizam insumos para formar uma unidade adicional de capital, a expansão generalizada dos custos de insumos contribuiu para retrair o investimento no país. A ausência das subvençôes tende a reduzir a taxa de crescimento do PIB abaixo do baseline e o emprego acompanha essa retração, apesar da redução do salário real, como pode ser visto na Tabela 3. Dessa forma, os custos dos fatores primários se reduziram como resposta à diminuição da demanda por fatores, pressionando-os nos primeiros períodos após a retirada das subvençōes.

O auge do declínio desses custos ocorreu no ano de 2015 (Figura 2). O salário médio acompanhou a trajetória de crescimento do emprego alguns períodos após a simulação dos choques. No final de 2030, o efeito sobre o emprego nacional ficaria praticamente um pouco abaixo do emprego tendencial. Os desvios negativos dos salários reais nos últimos anos voltariam a estimular sensivelmente o emprego nacional, já que o custo do trabalho por unidade de produto foi reduzido.

Assim como no mercado de trabalho, a queda da atividade na economia brasileira gerou uma retração nos requisitos de capital no processo produtivo. Consequentemente, percebe-se uma pressão de baixa da renda do capital, principalmente nas atividades intensivas no mesmo. Essa queda de rentabilidade reduz as taxas de retornos dos investimentos na economia e os custos de produção, retraindo os investimentos. 
TABELA 3

Variação acumulada (em ) dos principais agregados macroeconômicos

\begin{tabular}{|c|c|c|c|c|c|c|c|}
\hline Variáveis & 2011 & 2012 & 2013 & 2014 & 2015 & 2016 & $\begin{array}{l}2011- \\
2030\end{array}$ \\
\hline PIB & $-0,00277$ & $-0,0042319$ & $-0,0063483$ & $-0,0098734$ & $-0,0118222$ & $-0,0126507$ & $-0,0215954$ \\
\hline $\begin{array}{l}\text { Consumo das } \\
\text { Famílias }\end{array}$ & $-0,0045221$ & $-0,0079714$ & $-0,0121463$ & $-0,0175637$ & $-0,018824$ & $-0,0202238$ & $-0,0245645$ \\
\hline Exportaçōes & 0,0088557 & 0,0212137 & 0,0349368 & 0,0498798 & 0,0462256 & 0,045725 & $-0,0212283$ \\
\hline Importações & $-0,0114942$ & $-0,0226631$ & $-0,0361493$ & $-0,0527612$ & $-0,0521444$ & $-0,0515381$ & $-0,0195609$ \\
\hline Termos de troca & $-0,008721$ & $-0,020601$ & $-0,034133$ & $-0,049083$ & $-0,045319$ & $-0,044661$ & 0,021549 \\
\hline Emprego & $-0,0047205$ & $-0,0059237$ & $-0,0076959$ & $-0,0110888$ & $-0,0113475$ & $-0,0096213$ & $-0,0001364$ \\
\hline Salário Real & $-0,0029764$ & $-0,0067937$ & $-0,0117025$ & $-0,019372$ & $-0,0262721$ & $-0,0319197$ & $-0,0661385$ \\
\hline Salário Nominal & $-0,0191325$ & $-0,0404733$ & $-0,0667433$ & $-0,0967507$ & $-0,0943398$ & $-0,095349$ & $-0,0519979$ \\
\hline Investimento & $-0,0110724$ & $-0,0200058$ & $-0,0305783$ & $-0,0484709$ & $-0,0634521$ & $-0,0702495$ & $-0,0392264$ \\
\hline $\begin{array}{l}\text { Investimento em } \\
\text { capital físico }\end{array}$ & $-0,011256$ & $-0,020494$ & $-0,031266$ & $-0,049508$ & $-0,064785$ & $-0,071911$ & $-0,039427$ \\
\hline $\begin{array}{l}\text { Estoque de } \\
\text { capital físico }\end{array}$ & 0 & $-0,000887$ & $-0,002519$ & $-0,005028$ & $-0,008288$ & $-0,011454$ & $-0,039306$ \\
\hline $\begin{array}{l}\text { Investimento em } \\
\text { capital de conhe- } \\
\text { cimento }\end{array}$ & $-0,006478$ & $-0,007885$ & $-0,013164$ & $-0,022426$ & $-0,031854$ & $-0,032772$ & $-0,04078$ \\
\hline $\begin{array}{l}\text { Estoque de } \\
\text { capital de conhe- } \\
\text { cimento }\end{array}$ & 0 & $-0,000999$ & $-0,002074$ & $-0,003748$ & $-0,006623$ & $-0,010141$ & $-0,034895$ \\
\hline Deflator do PIB & $-0,0181902$ & $-0,0378962$ & $-0,0615231$ & $-0,0855669$ & $-0,0751626$ & $-0,0707282$ & 0,0116234 \\
\hline $\begin{array}{l}\text { Índice de preços } \\
\text { ao consumidor }\end{array}$ & $-0,02$ & $-0,03$ & $-0,06$ & $-0,08$ & $-0,07$ & $-0,06$ & 0,01 \\
\hline $\begin{array}{l}\text { Índice de preços } \\
\text { do investimento }\end{array}$ & $-0,02$ & $-0,04$ & $-0,06$ & $-0,08$ & $-0,07$ & $-0,06$ & 0,02 \\
\hline Bem-estar & $-0,008463$ & $-0,014568$ & $-0,021697$ & $-0,031022$ & $-0,034513$ & $-0,039095$ & $-0,04525$ \\
\hline
\end{tabular}

Fonte: Elaborada pela autora com base nos resultados da simulaçáo

Conforme o movimento defasado estabelecido na função de acumulação de capital, a redução dos investimentos no ano corrente provocou uma diminuição do estoque de capital físico e de conhecimento nos anos subsequentes, repercutindo positivamente sobre a taxa de retorno esperada e, assim, sobre os investimentos na economia. $\mathrm{O}$ resultado da sequência deste processo é a convergência dos investimentos e capital em relaçáa ao baseline da economia. A partir de 2020, quando se iniciou um aquecimento de demanda dos fatores primários, a queda do preço do capital começou a suavizar-se, de tal modo que, em 2028, inverteu-se a trajetória, desviando positivamente (Figura 2). 
FIGURA 2

Trajetórias dos preços dos fatores primários após a simulaçáo (não deflacionados)

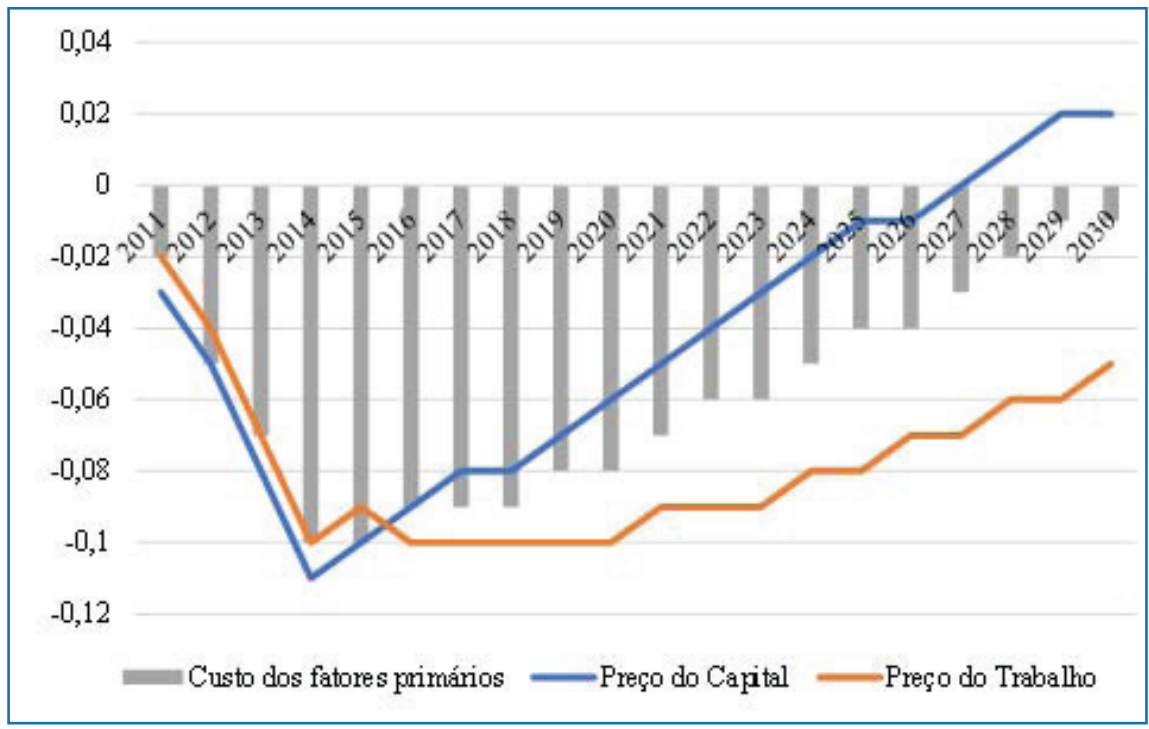

Fonte: Elaborada pelos autores

A rentabilidade do capital ascendente contribuiu positivamente para a taxa de retorno esperada dos investimentos e, assim, amortizou as variaçóes negativas dos investimentos na economia. Como a queda da rentabilidade do capital diminui as taxas de retorno potenciais, nos primeiros períodos após a simulação do choque, o investimento agregado apresenta trajetória declinante.

A ausência das subvençóes resulta no declínio dos investimentos mais acentuadamente nos primeiros períodos após o choque, o que implica uma queda contínua do estoque dos capitais (Figura 3).

As reduçóes dos custos internos da economia nos primeiros anos após a eliminação das subvençôes induziram a uma taxa de crescimento das exportaçóes acima do cenário de referência no país até 2020. Assim, a política tornaria os produtos domésticos relativamente mais competitivos, refletindo a trajetória declinante dos custos de produção. Como os choques simulados ocorrem sobre os setores que demandaram os recursos concedidos pela Finep, setores como a produção de commodities e extração de produtos primários são atingidos marginalmente pela retração das atividades produtivas. Por essa razão, percebe-se que as exportaçóes brasileiras se expandem até o biênio 2015-2016, mas declinam nos períodos subsequentes (Tabela 3). 
FIGURA 3

Evoluçáo das trajetórias do investimento e do estoque de capitais físico (KF) e de conhecimento (KC)

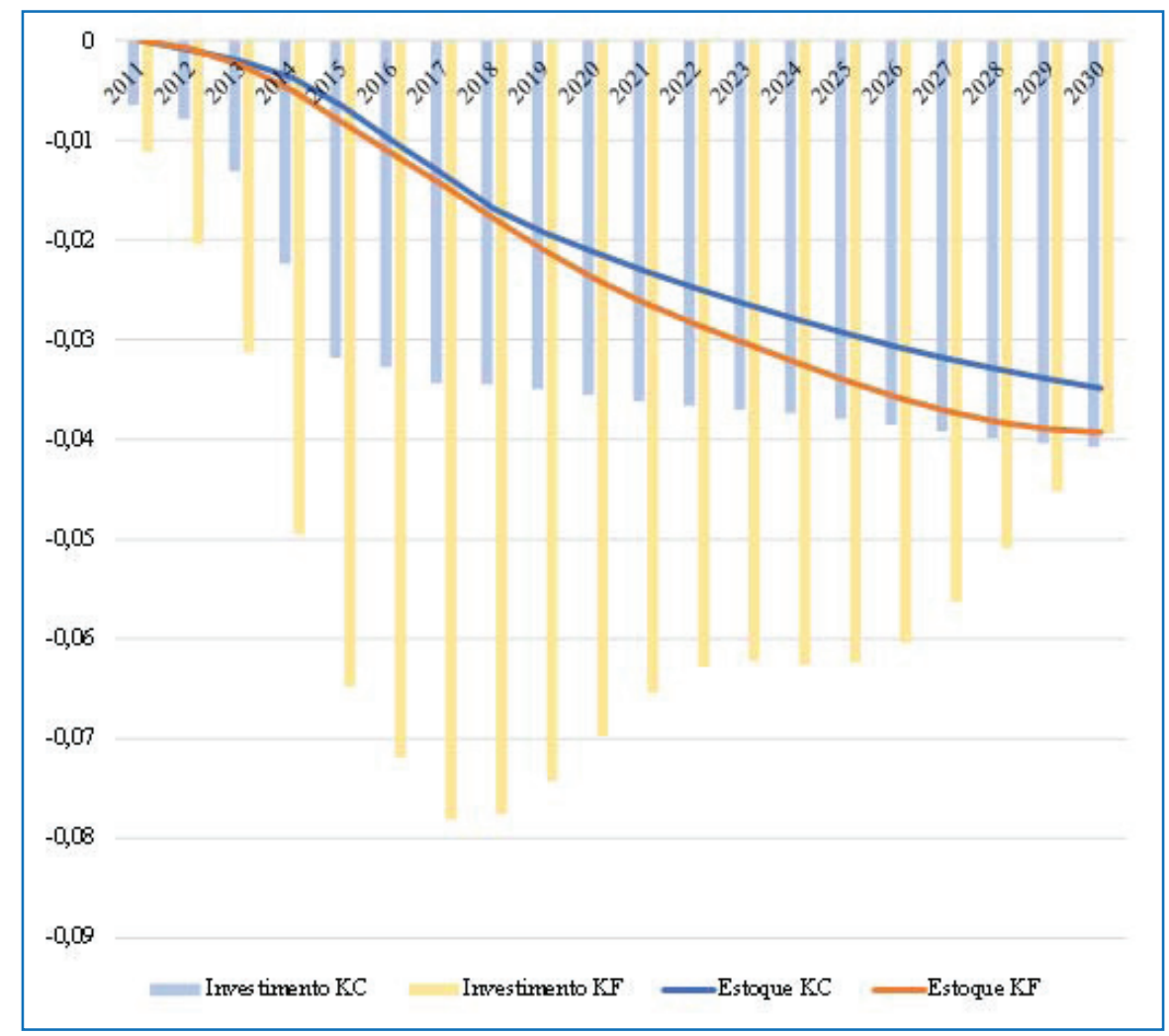

Fonte: Elaborada pelos autores

Por outro lado, dada a possibilidade de substituição entre bens domésticos e importados, os desvios negativos dos preços internos desestimularam as importações até 2030. Os termos de troca reduziram-se inicialmente, reforçados pela retração produtiva no Brasil. Além da concorrência com produtos nacionais, a demanda dos bens importados decaiu em razão da queda da produção interna, que requer direta e indiretamente insumos importados. Portanto, o corte das subvençóes promoveu um superávit marginal na balança comercial brasileira no longo prazo, cuja variaçáo se dá pela queda das importaçôes.

Por fim, cabe registrar os impactos da política sobre o consumo das famílias. Destaca-se que, no modelo, o consumo das famílias se move endogenamente para equilibrar as variaçóes do PIB do lado da renda e do lado do dispêndio (HORRIDGE, 2006). Logo, o corte dos valores subvencionados gera impacto negativo sobre a 
renda dos fatores primários que, no agregado, afeta o consumo das famílias. Como estas maximizam sua utilidade ampliando o consumo, então a política de corte das subvençóes de produção diminui o bem-estar das mesmas.

Portanto, considerando as trajetórias desses indicadores macroeconômicos, conclui-se que a ausência da política de concessão de subvenções gera efeitos contracionistas sobre os principais componentes de absorção de demanda no mercado interno, cujos impactos negativos foram minorados pelo saldo marginal da balança comercial e pelo crescimento da demanda do mercado externo.

\subsection{Efeitos setoriais}

Devido às assimetrias na estrutura de custos e de demanda, os setores econômicos respondem distintamente às políticas simuladas. Setores intensivos em trabalho teriam mais facilidade para ajustar os custos de produção em relação à queda de demanda, ao passo que atividades intensivas em capital, cuja oferta do fator primário é mais inelástica ao longo dos anos, teriam maior dificuldade de ajuste, levando a uma retração de atividade relativamente maior.

Para facilitar a análise de alguns resultados, foi feita uma agregação com base na intensidade tecnológica dos setores produtivos (OCDE, 2011). Além do agrupamento sugerido pela OCDE visualizado no Quadro 2, também foram agregados os setores de atividades denominadas "KIBS" (Knowledge Intensive Business), de serviços e aqueles ligados às atividades agropecuárias - setores tradicionalmente não demandantes de P\&D.

Os setores de produtos farmacêuticos e o de materiais eletrônicos e de comunicação, por exemplo, exigem mão de obra especializada e estrutura produtiva dotada de tecnologias avançadas, fazendo com que os custos de produção sejam elevados, além do que, no período analisado, receberam recursos de subvençóes em praticamente todos os anos de concessão. Por essas razóes, percebe-se que um corte nas subvençôes acarreta uma queda expressiva no valor adicionado e na rentabilidade do capital nessas atividades. Com isso, houve reduçâo da taxa de retorno e do investimento setorial (Figura 4). 
QUADRO 2

Classificaçáo dos setores produtivos por intensidade tecnológica segundo OCDE

\begin{tabular}{|c|c|}
\hline Setores de Alta Intensidade Tecnológica & Setores de Médio-Alta Intensidade Tecnológica \\
\hline Aeronaves e naves espaciais & Máquinas e aparelhos elétricos \\
\hline Indústria farmacêutica & Veículos a motor, reboques e semi-reboques \\
\hline $\begin{array}{l}\text { Equipamentos de escritório, contabilidade } \\
\text { e informática }\end{array}$ & Indústria química, exceto a farmacêutica \\
\hline Rádio, TV e equipamentos de comunicação & $\begin{array}{l}\text { Equipamentos ferroviários e equipamentos de } \\
\text { transporte }\end{array}$ \\
\hline Instrumentos médicos, ópticos e de precisão & Máquinas e equipamentos \\
\hline Setores de Médio-Baixa Intensidade Tecnológica & Setores de Baixa Intensidade Tecnológica \\
\hline Construção e reparaçáo de navios e barcos & Produtos de manufatura e reciclagem \\
\hline Produtos de borracha e plásticos & $\begin{array}{l}\text { Madeira, celulose, papel, produtos de papel, } \\
\text { impressão e publicaçáo }\end{array}$ \\
\hline $\begin{array}{l}\text { Coque, produtos petrolíferos refinados e } \\
\text { combustível nuclear }\end{array}$ & Alimentos, bebidasd e produtos de tabaco \\
\hline Outros produtos minerais não metálicos & Têxteis, produtos têxteis, couro e calçados \\
\hline $\begin{array}{l}\text { Indústria metalúrgica básica e outros } \\
\text { produtos de metal }\end{array}$ & \\
\hline
\end{tabular}

Fonte: OCDE (2011).

FIGURA 4

Trajetória do valor adicionado em relaçáo ao investimento agregado de setores selecionados após o choque

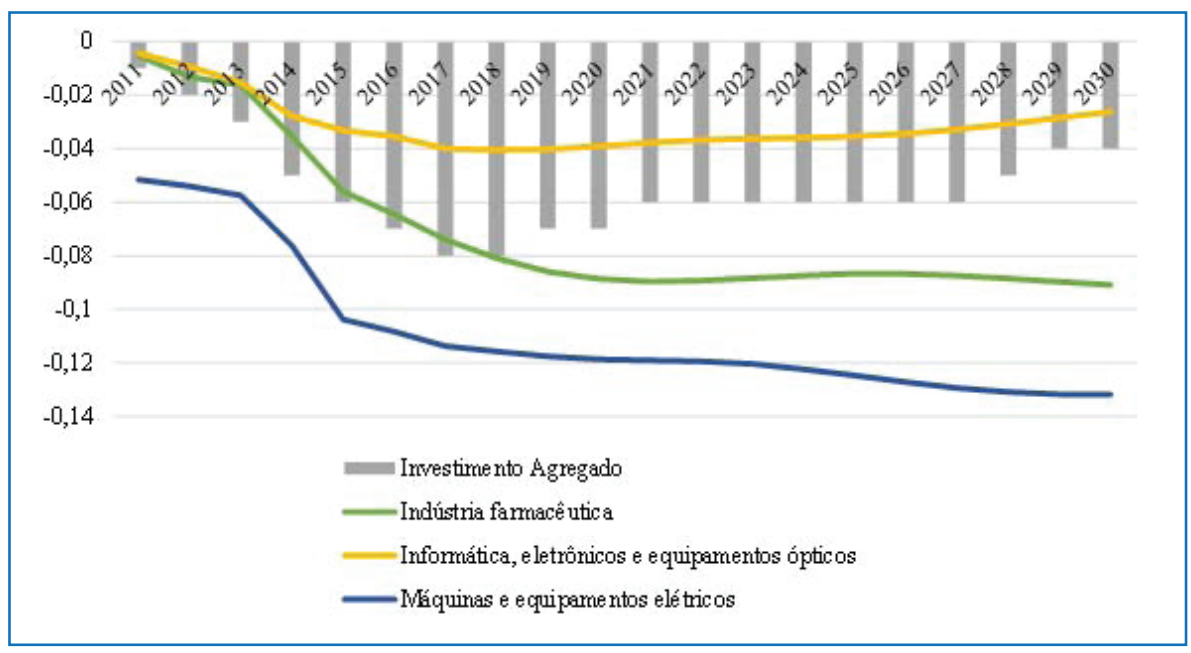

Fonte: Elaborada pelos autores 
Com o corte das subvençóes, os investidores esperam um menor retorno frente à queda da rentabilidade tanto do capital físico, quanto do capital de conhecimento. Assim, a rentabilidade do capital pode indicar o quanto as atividades produtivas da economia estão requisitando tal insumo, em resposta à retração da atividade econômica. Dada uma queda na rentabilidade de ambos os tipos de capital, os setores econômicos reduzem a demanda pelos fatores e diminuem o investimento produtivo, reduzindo os estoques dos mesmos e comprometendo a FBCF da economia.

O resultado sobre os investimentos em capital físico para setores intensivos mostra que tais investimentos foram mais afetados durante todo o período - observado e projetado. Ao serem eliminadas as subvençôes, o aumento dos custos produtivos gera redução na demanda dos fatores primários, inclusive do capital, situação essa semelhante à que ocorreu com os setores mais intensivos em capital de conhecimento.

Para os setores mais intensivos na utilização do fator trabalho (Tabela 4), o choque simulado de retirada dos recursos de subvenção gerou efeitos de ordem secundária, determinados pelo efeito-atividade do mesmo. Ao reduzir a produção, uma menor demanda por fatores primários faz com que o preço destes seja reduzido. Assim, tem-se um resultado de queda dos salários nominais.

A Tabela 4 fornece a variação percentual no nível dos empregos em setores mais intensivos em trabalho após a simulação.

TABELA 4

Nível de emprego após a simulaçáo do choque para setores

\begin{tabular}{|c|c|c|c|c|c|c|c|}
\hline \multirow[b]{2}{*}{ Setores } & \multicolumn{7}{|c|}{ Emprego } \\
\hline & 2011 & 2012 & 2013 & 2014 & 2015 & 2016 & $\begin{array}{r}2011- \\
2030\end{array}$ \\
\hline Serviços Domésticos & 1,80 & 2,67 & 1,66 & 6,26 & $-4,46$ & $-5,08$ & 2,62 \\
\hline Educação Pública & 0,10 & 2,23 & 0,51 & 2,91 & 0,98 & 2,60 & 0,16 \\
\hline Saúde Pública & 0,10 & 2,41 & 0,47 & 3,12 & 1,17 & 2,55 & 0,22 \\
\hline Educação Privada & 3,14 & 3,48 & 2,48 & 6,00 & $-4,71$ & $-5,86$ & 2,13 \\
\hline $\begin{array}{l}\text { Vigiliância, segurança e } \\
\text { investigaçáo }\end{array}$ & 1,49 & 1,89 & 1,63 & 3,10 & $-1,11$ & $-1,13$ & 1,70 \\
\hline $\begin{array}{l}\text { Administração pública, } \\
\text { defesa e seguridade social }\end{array}$ & $-0,08$ & 2,37 & 0,35 & 3,21 & 1,09 & 2,63 & 0,45 \\
\hline
\end{tabular}

Fonte: Elaborada pela autora com base nos resultados da simulação 
Dessa maneira, é possível perceber as relações existentes entre o grau tecnológico nos setores e a utilização do capital de conhecimento como fator primário. Os impactos foram sensivelmente maiores para os setores de alta e médio-alta intensidade tecnológica, enquanto para os setores de baixa intensidade tecnológica e para aqueles ligados às atividades agropecuárias, a retração foi nitidamente menor (Tabela 5).

TABELA 5

Evoluçáo do nível de produçáo no período (em acumulado)

\begin{tabular}{l|c|c|c|c|c|c|c}
\hline $\begin{array}{c}\text { Setores por } \\
\text { intensidade } \\
\text { tecnológica }\end{array}$ & $\mathbf{2 0 1 1}$ & $\mathbf{2 0 1 2}$ & $\mathbf{2 0 1 3}$ & $\mathbf{2 0 1 4}$ & $\mathbf{2 0 1 5}$ & $\mathbf{2 0 1 6}$ & $\begin{array}{l}\mathbf{2 0 1 1 -} \\
\mathbf{2 0 3 0}\end{array}$ \\
\hline Alta & $-0,0048$ & $-0,0110$ & $-0,0157$ & $-0,0309$ & $-0,0423$ & $-0,0467$ & $-0,0516$ \\
Médio-Alta & $-0,0057$ & $-0,0049$ & $-0,0065$ & $-0,0115$ & $-0,0183$ & $-0,0199$ & $-0,0402$ \\
Médio-Baixa & $-0,0015$ & $-0,0006$ & 0,0004 & $-0,0005$ & $-0,0023$ & $-0,0018$ & $-0,0264$ \\
Baixa & 0,0002 & 0,0012 & 0,0027 & 0,0039 & 0,0035 & 0,0033 & $-0,0179$ \\
Serviços (P\&D) & $-0,0014$ & $-0,0020$ & $-0,0031$ & $-0,0050$ & $-0,0070$ & $-0,0087$ & $-0,0233$ \\
KIBS & $-0,0032$ & $-0,0043$ & $-0,0086$ & $-0,0138$ & $-0,0205$ & $-0,0238$ & $-0,0386$ \\
Outros serviços & $-0,0030$ & $-0,0049$ & $-0,0075$ & $-0,0115$ & $-0,0136$ & $-0,0146$ & $-0,0198$ \\
Agropecuária & 0,0005 & 0,0018 & 0,0036 & 0,0059 & 0,0076 & 0,0086 & $-0,0190$ \\
\hline
\end{tabular}

Fonte: Elaborada pela autora com base nos resultados da simulação.

A retração da demanda por fatores primários na economia após o choque é mais sentida pelos setores de alta intensidade tecnológica, os setores KIBS e os de médio-alta tecnologia. Esses apresentaram redução expressiva da demanda por insumos primários nos primeiros períodos após o choque e sinalizam apenas a estabilização no longo prazo (Figura 5).

A Figura 6 ilustra a trajetória para a formação dos estoques de capital de conhecimento (KC) e de capital físico (KF) nos setores tecnologicamente mais intensivos e nos setores KIBS após o corte das subvençôes. Esse resultado é relacionado com a baixa atratividade de investimentos em bens de capital devido ao aumento dos custos dos mesmos. A retração da formação de estoques de capital físico e de conhecimento também ocorreu para os setores menos intensivos em tecnologia, mas de modo mais suave e menos persistente ao longo do tempo. 
FIGURA 5

Trajetória da demanda por fatores primários após o choque

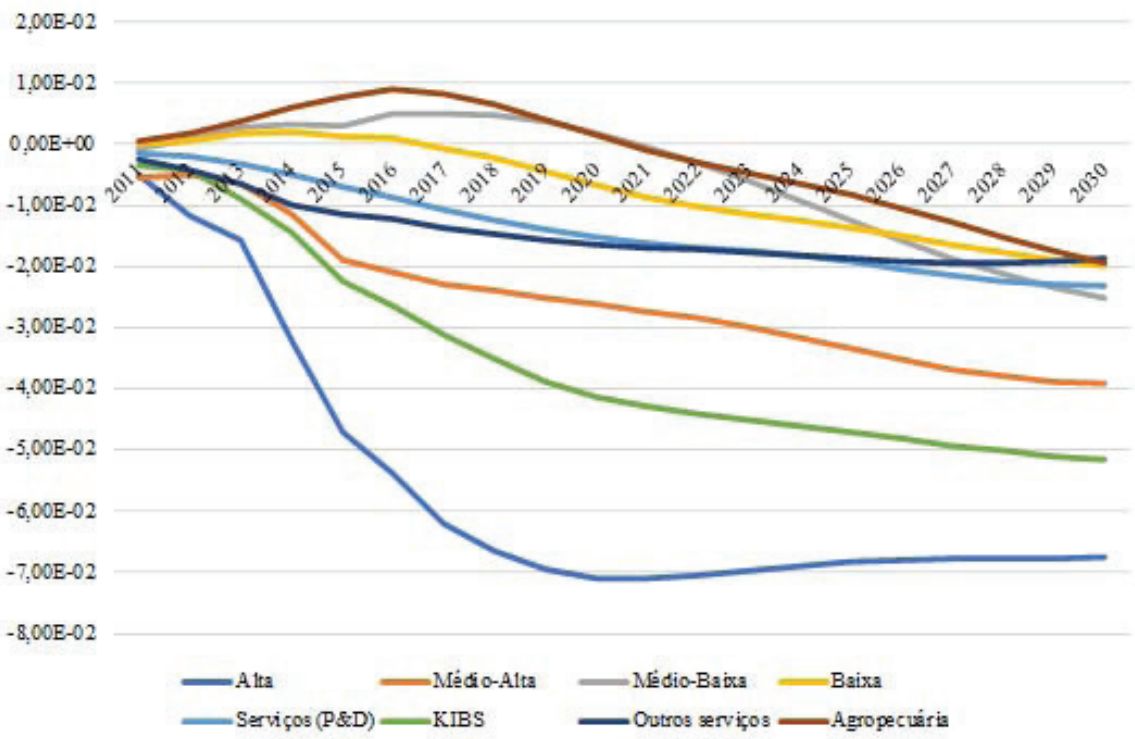

Fonte: Elaborada pelos autores.

FIGURA 6

Evoluçáo dos estoques de capital para os setores mais intensivos em tecnologia e os KIBS

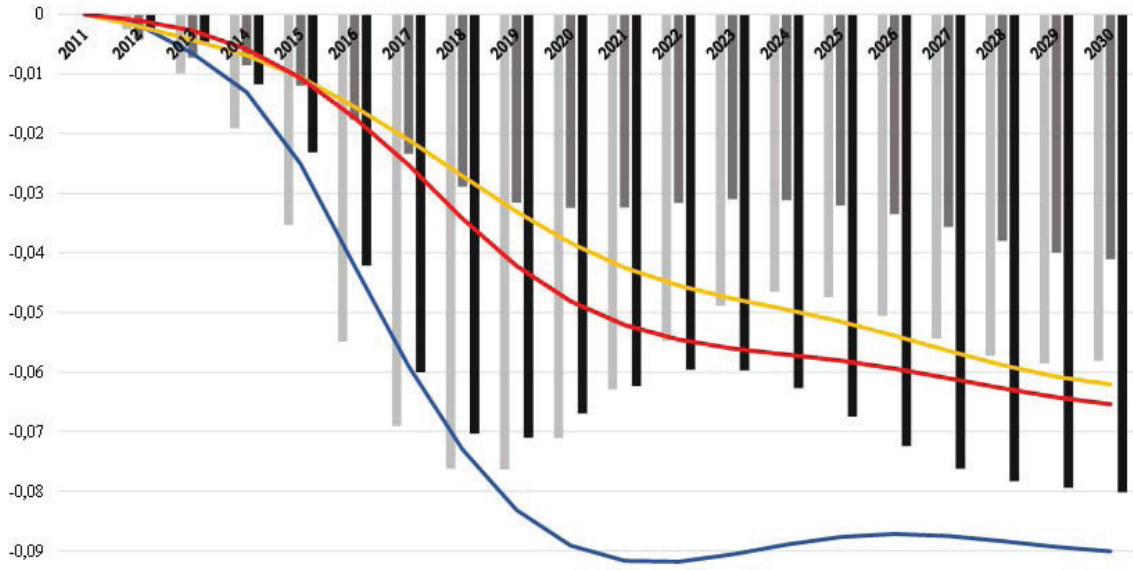

$-0,1$

Alta - KC $=$ Médio-Alta - KC

Fonte: Elaborada pelos autores. 
Os valores da Tabela 6 denotam que, para os setores de atividades agropecuárias e de médio-baixa intensidade tecnológica, a diminuição dos estoques de capital de conhecimento só ocorreu alguns períodos posteriores ao choque - o que está de acordo com a estrutura produtiva tradicionalmente não demandante desse tipo de capital.

\section{Tabela 6}

Valores da evoluçáo da formaçáo de estoques de capital de conhecimento e físico para setores selecionados

\begin{tabular}{l|c|c|c|c|c|c|c}
\hline $\begin{array}{c}\text { Setores por intensi- } \\
\text { dade tecnológica }\end{array}$ & $\mathbf{2 0 1 1}$ & $\mathbf{2 0 1 2}$ & $\mathbf{2 0 1 3}$ & $\mathbf{2 0 1 4}$ & $\mathbf{2 0 1 5}$ & $\mathbf{2 0 1 6}$ & $\begin{array}{c}\mathbf{2 0 1 1 -} \\
\mathbf{2 0 3 0}\end{array}$ \\
\hline Médio-Baixa - KC & 0,0000 & 0,0006 & 0,0025 & 0,0061 & 0,0104 & 0,0134 & $-0,0253$ \\
Baixa - KC & 0,0000 & 0,0003 & 0,0005 & 0,0008 & 0,0016 & 0,0027 & $-0,0241$ \\
Outros serviços - KC & 0,0000 & 0,0003 & 0,0003 & $-0,0002$ & $-0,0007$ & $-0,0003$ & $-0,0175$ \\
Agropecuária - KC & 0,0000 & 0,0010 & 0,0029 & 0,0052 & 0,0076 & 0,0084 & $-0,0154$ \\
Médio-Baixa - KF & 0,0000 & 0,0004 & 0,0017 & 0,0039 & 0,0065 & 0,0085 & $-0,0367$ \\
Baixa - KF & 0,0000 & $-0,0001$ & $-0,0003$ & $-0,0007$ & $-0,0015$ & $-0,0034$ & $-0,0468$ \\
Outros serviços - KF & 0,0000 & $-0,0012$ & $-0,0035$ & $-0,0071$ & $-0,0116$ & $-0,0156$ & $-0,0381$ \\
Agropecuária - KF & 0,0000 & 0,0006 & 0,0021 & 0,0044 & 0,0068 & 0,0080 & $-0,0227$ \\
\hline
\end{tabular}

Fonte: Elaborada pela autora com base nos resultados da simulaçáo

A formação dos estoques de capital na economia gera sinais de como a economia irá evoluir prospectivamente. A reduçáo nos estoques de ambos os tipos de capital de modo persistente e sem indícios de recuperaçáo no longo prazo indica que a atividade econômica não deve apresentar trajetória de crescimento durante o período observado.

\section{Conclusões}

O objetivo central desta aplicação do modelo BIM-KC foi verificar como o programa de concessão de subvençôes econômicas à inovação afeta os principais indicadores macroeconômicos e setoriais na economia brasileira. Esta pesquisa foi conduzida a fim de contornar as dificuldades encontradas por um modelo tradicional de EGC em relação ao aspecto de investimento em $\mathrm{P} \& \mathrm{D}$, desenvolvendo uma nova abordagem para a modelagem do investimento em capital de conhecimento para o Brasil. Mediante uma simulação na qual os recursos concedidos pelo programa ao longo dos anos de 2010 a 2016 foram retirados da economia, chegou-se à conclusão de que os indicadores foram impactados com a ausência dos mesmos. 
A partir da suposição de que os projetos de inovação das empresas continuariam sendo executados, houve uma alteração na estrutura de custos de produção das atividades econômicas. $\mathrm{O}$ mecanismo de propagação do choque simulado revelou que indicadores como renda e investimentos foram negativamente afetados, assim como houve desaquecimento da atividade econômica por meio de uma menor demanda interna, menor nível de produção dos setores e uma menor demanda por fatores primários. Ademais, com a redução dos estoques de capital físico e de conhecimento resultante da ausência dos recursos de subvençáo, contraiu-se a FBCF, o que significa uma redução da capacidade produtiva futura por meio de investimentos correntes em ativos fixos.

Outra questão abordada foi averiguar como seriam setorialmente desagregados os efeitos da simulação, revelando quais seriam os setores produtivos mais afetados pelos incentivos à inovação. Verificou-se que os setores econômicos que receberam maior quantidade de recursos de subvençôes econômicas apresentariam uma maior retraçáo da produçáo, provocando queda no valor adicionado dos mesmos em comparação com atividades que náo receberam ou que pouco receberam recursos de subvenção no período analisado.

Assim, os efeitos da ausência das subvençôes geram impactos distintos sobre as atividades econômicas, causando alguma distorção no setor produtivo como um todo. Observando a trajetória do valor adicionado em relação ao investimento agregado de setores mais intensivos em capital físico e capital de conhecimento, percebe-se uma trajetória declinante abaixo dos níveis de retração do investimento agregado.

No geral, os benefícios econômicos dos dispêndios públicos em atividades de $\mathrm{P} \& \mathrm{D}$ superaram suas desvantagens - como resultados dissonantes nos setores produtivos - e demonstram ser relevantes para a economia brasileira, uma vez que, observando por outra ótica, tem-se que a promoção das atividades de $P \& D$ viria a gerar maior acúmulo de capital de conhecimento e ampliaria a capacidade de geração de P\&D no longo prazo.

Pode-se concluir que os recursos concedidos geraram efeitos sobre toda a economia e ampliaram a geração de inovaçáo tecnológica por meio do investimento em capital de conhecimento, embora a concessão de subvençóes seja uma política de curto alcance (pequeno número de empresas beneficiadas) e esteja inserida num contexto de baixa utilizaçáo dos mecanismos de apoio à inovaçáo pelas empresas no Brasil - sendo que a efetividade dos mesmos depende da adesão do setor produtivo. 
$\mathrm{O}$ avanço desta pesquisa em relação à compreensão dos efeitos econômicos dinâmicos da acumulaçáo de capital de conhecimento e da produção de $\mathrm{P} \& \mathrm{D}$ pode ser aprimorado pela inserção dos gastos do governo como componente endógeno no modelo. Assim, questôes pertinentes ao equilíbrio fiscal poderiam ser abordadas, tornando a análise dos impactos de políticas públicas de inovação mais completa, constituindo-se numa agenda de pesquisa relevante para aqueles que desejam avaliar corretamente os efeitos econômicos desse tipo de política pública.

\section{Referências}

ARAÚJO, B.C. et al. Impactos dos fundos setoriais nas empresas. Revista Brasileira de Inovaçấo, v. 11, p. 85-112, 2012.

Armington, P.S., A theory of demand for products distinguished by place of production. Int. Monetary Fund Staff Pap. 16, 159-178. 1969.

AVELLAR, A.P. Impacto das políticas de fomento à inovação no Brasil sobre o gasto em atividades inovativas e em atividades de P\&D das empresas. Estudos Econômicos, v. 39, n. 3, p. 629-649, 2009.

AVELLAR, A.P.M.; ALVES, P.F. Avaliação de Impacto de Programas de Incentivos Fiscais a Inovação - Um Estudo sobre os Efeitos do PDTI no Brasil. Revista EconomiA, v. 9, n. 1, p. 143-164, jan./abr. 2008.

BOR, Y.J. et al. A dynamic general equilibrium model for public R\&D investment in Taiwan. Economic Modelling, v. 27, n. 1, p. 171-183, 2010.

BRASIL. Lei n. 8.248, de 23 de outubro de 1991, aperfeiçoada pela Lei n. 11.077, de 30 de dezembro de 2004. Diário Oficial da Uniāo, Brasília, DF, 31 dez. 2004.

BUENO, A.; TORKOMIAN, A.L.V. Financiamentos à inovação tecnológica: reembolsáveis, não reembolsáveis e incentivos fiscais. RAI Revista de Administração e Inovação, v. 11, n. 4, p. 135-158, 2014.

BYE, B.; FAEHN, T.; GRÜNFELD, L.A. Growth and innovation policy in a small, open economy: should you stimulate domestic R\&D or exports? The BE Journal of Economic Analysis \& Policy, v. 11, n. 1, p. 1-41, 2011.

BYE, B.; FÆHN, T.; HEGGEDAL, T.-R. Welfare and growth impacts of innovation policies in a small, open economy; an applied general equilibrium analysis. Economic Modelling, v. 26, n. 5, p. 1075-1088, 2009. 
CBO, U.S. R\&D and Productivity Growth: A Background Paper. Washington, DC: The Congress of the United States (Congressional Budget Office), 2005. Disponível em https:// www.cbo.gov/sites/default/files/cbofiles/ftpdocs/64xx/doc6482/06-17-r-d.pdf. Acesso em: 22 ago. 2018.

CHEN, Zhenhua. Measuring the regional economic impacts of high-speed rail using a dynamic SCGE model: the case of China. European Planning Studies, v. 27, n. 3, p. 483-512, 2019.

CLARK, J.; GUY, K. Innovation and competitiveness: a review: Practitioners' forum. Technology Analysis \& Strategic Management, v. 10, n. 3, p. 363-395, 1998.

COELHO, D.S.C.; DE NEGRI, J.A. Impacto do financiamento do BNDES sobre a produtividade das empresas: Uma aplicação do efeito quantílico de tratamento. Niterói: Associação Nacional dos Centros de Pós-graduação em Economia - Anpec, 2011.

DIAO, X. et al. A dynamic CGE model: An application of R\&D-based endogenous growth model theory. University of Minnesota, Economic Development Center, 1996.

DIXON, P. B. Orani, a multisectoral model of the Australian economy. North Holland, 1982.

DOSI, G.; PAVITT, K.; SOETE, L. The economics of technical change and international trade. London: Harvester Wheastsheaf, 1990.

FINEP. Subvenção Econômica. 2017. Disponível em: http://finep.gov.br/afinep/122-apoio-e-financiamento/tipos-de-apoio/subvencao-economica. Acesso em: 5 abr. 2017.

GARAU, G.; LECCA, P. Impact analysis of regional knowledge subsidy: a CGE approach. Centre for North South Economic Research, University of Cagliari and Sassari, Sardinia, 2008. (Working Paper CRENoS).

GHOSH, M. R\&D policies and endogenous growth: a dynamic general equilibrium analysis of the case for Canada. Review of development economics, v. 11, n. 1, p. 187-203, 2007.

GRILICHES, Zvi. The search for R\&D spillovers. National Bureau of Economic Research, 1991.

HALL, Bronwyn H. The stock market's valuation of R\&D investment during the 1980's. The American Economic Review, v. 83, n. 2, p. 259-264, 1993.

HONG, J. et al. Do government grants promote innovation efficiency in China's high-tech industries? Technovation, v. 57, p. 4-13, 2016.

HORRIDGE, M. ORANI-G: A generic single-country computable general equilibrium model. Australia, Centre of Policy Studies and Impact Project, Monash University, 2006. 
HORRIDGE, M.; PARMENTER, B.R.; PEARSON, K.R. ORANI-G: A general equilibrium model of the Australian economy. Australia, Centre of Policy Studies and Impact Project, Monash University, 2000.

HORTA, G.T. de L.; GIAMBIAGI, F. Perspectivas DEPEC 2018: o crescimento da economia brasileira 2018-2023. Rio de Janeiro: BNDES, 2018. 60 p.

JAUMOTTE, F; PAIN, N. An overview of public policies to support innovation. No 456, OECD Publishing, 2005.

KANNEBLEY JUNIOR, S.; PORTO, G. Incentivos Fiscais à Pesquisa, Desenvolvimento e Inovação no Brasil. BID, Technical Report, set. 2012. (Documento para Discussão, IDB-DP-236).

KLEIN, L. R.; RUBIN, H. A constant-utility index of the cost of living. The Review of Economic Studies, v. 15, n. 2, p. 84-87, 1947.

KŘÍSTKOVÁ, Z. Impact of R\&D investment on economic growth of the Czech Republic-a recursively dynamic CGE Approach. Prague economic papers, v. 21, n. 4, 2012.

LOS, B.; VERSPAGEN, B. R\&D spillovers and productivity: evidence from US manufacturing microdata. Empirical economics, v. 25, n. 1, p. 127-148, 2000.

MAZZUCATO, M. O Estado Empreendedor: desmascarando o mito do setor público vs. setor privado. São Paulo: Editora Portfolio-Penguin, 2014.

MORAIS, J.M. de. Uma avaliação de programas de apoio financeiro à inovação tecnológica com base nos Fundos Setoriais e na Lei de Inovação. In: DE NEGRI, J.A.; KUBOTA, L.C. (ed.). Políticas de incentivo à inovação tecnológica no Brasil. Brasília: Ipea, 2008. p. 68-105.

MORAIS, J.M. de. A subvenção econômica cumpre a função de estímulo à inovação e ao aumento da competitividade das empresas brasileiras? In: MONTEIRO NETO, A. (coord.). Brasil em desenvolvimento: Estado, planejamento e políticas públicas. Brasília: Ipea, 2012. p. 343-357.

NADIRI, M.I.; PRUCHA, I.R. Estimation of the depreciation rate of physical and R\&D capital in the US total manufacturing sector. Economic Inquiry, v. 34, n. 1, p. 43-56, 1996.

OECD. ORGANIZAÇÃO PARA A COOPERAÇÃO E O DESENVOLVIMENTO ECONÔMICO. Oslo Manual. Guideliness for collecting and interpreting innovation data. 3rd ed. Paris: OECD, 2005.

OECD. ORGANIZAÇÃO PARA A COOPERAÇÃO E O DESENVOLVIMENTO ECONÔMICO. Classification of manufacturing industries into categories based on R\&D 
intensities. 2011. Disponível em: https://www.oecd.org/sti/ind/48350231.pdf. Acessado em: 09/12/2018.

VISSER, S. RひD in Worldscan. CPB Netherlands Bureau for Economic Policy Analysis, 2007.

WOLFF, E.N. Spillovers, linkages and technical change. Economic Systems Research, v. 9, n. 1, p. 9-23, 1997.

YEO, Y. et al. Study on the effect of innovation on employment structure and economic growth: A computable general equilibrium approach. EcoMod, 2016.

ZAWALIŃSKA, K.; TRAN, N.; PŁOSZAJ, A. Planning R\&D in a Post Centrally-Planned Economy: Assessing the Macroeconomic Effects in Poland. Centre for Policy Studies, Victoria University, 2016.

ZÜRN, M. et al. R\&D investment and knowledge input in a technology oriented CGE model. In: EcoMod Conference on Energy and Environmental Modelling, Moscow. 2007.

\section{Contribuiçáo dos autores:}

A. Fundamentação teórico-conceitual e problematização: Domitila Santos Bahia, Eduardo Gonçalves, Admir Antônio Betarelli Jr.

B. Pesquisa de dados e análise estatística: Domitila Santos Bahia, Admir Antônio Betarelli Jr.

C. Elaboração de figuras e tabelas: Domitila Santos Bahia.

D. Elaboração e redação do texto: Domitila Santos Bahia, Eduardo Gonçalves, Admir Antônio Betarelli Jr.

E. Seleção das referências bibliográficas: Domitila Santos Bahia, Eduardo Gonçalves, Admir Antônio Betarelli Jr.

Conflito de Interesse: os autores declaram não haver conflito de interesse

Fonte de Financiamento: Conselho Nacional de Desenvolvimento Científico e Tecnológico - CNPq, processos 425318/2018-4, 309632/2018-8,435499/2018-1 e 303781/2019-0; e Coordenação de Aperfeiçoamento de Pessoal de Nível Superior - CAPES, 001.

Este é um artigo publicado em acesso aberto (Open Access) sob a licença Creative Commons Attribution CC-BY, que permite uso, distribuição e reprodução em qualquer meio, sem restriçóes desde que o trabalho original seja corretamente citado 
ANEXO A

Lista de setores do modelo

\begin{tabular}{|c|c|}
\hline Siglas & Descrição do setor \\
\hline AgricultOut & Agricultura, inclusive o apoio à agricultura e a pós-colheita \\
\hline Pecuria & Pecuária, inclusive o apoio à pecuária \\
\hline FlorPescAq & Produção florestal; pesca e aquicultura \\
\hline CarvaoMNMet & Extração de carvão mineral e de minerais não metálicos \\
\hline PetrolGas & Extração de petróleo e gás, inclusive as atividades de apoio \\
\hline MinerioFerr & Extração de minério de ferro, inclusive beneficiamentos e a aglomeraçáo \\
\hline MMNFerro & Extração de minerais metálicos não ferrosos, inclusive beneficiamentos \\
\hline AbateCarne & Abate e produtos de carne, inclusive os produtos do laticínio e da pesca \\
\hline RefAcucar & Fabricação e refino de açúcar \\
\hline OtPAliment & Outros produtos alimentares \\
\hline Bebidas & Fabricação de bebidas \\
\hline PFumo & Fabricação de produtos do fumo \\
\hline PTexteis & Fabricação de produtos têxteis \\
\hline AVestuario & Confecção de artefatos do vestuário e acessórios \\
\hline CalcCouro & Fabricação de calçados e de artefatos de couro \\
\hline PdMadeira & Fabricação de produtos da madeira \\
\hline CelulPapel & Fabricação de celulose, papel e produtos de papel \\
\hline ImpressRep & Impressão e reprodução de gravaçôes \\
\hline RfPetrol & Refino de petróleo e coquerias \\
\hline Biocomb & Fabricação de biocombustíveis \\
\hline PQuimicos & Fabricação de químicos orgânicos e inorgânicos, resinas e elastômeros \\
\hline DefAgric & Fabricação de defensivos, desinfestantes, tintas e químicos diversos \\
\hline Perfuma & Fabricação de produtos de limpeza, cosméticos/perfumaria e higiene pessoal \\
\hline Farmac & Fabricação de produtos farmoquímicos e farmacêuticos \\
\hline BorraPlast & Fabricação de produtos de borracha e de material plástico \\
\hline PMNMeta & Fabricação de produtos de minerais não-metálicos \\
\hline FAcoDeriv & Produção de ferro-gusa/ferroligas, siderurgia e tubos de aço sem costura \\
\hline MetNFerros & Metalurgia de metais não-ferosos e a fundição de metais \\
\hline PMetal & Fabricação de produtos de metal, exceto máquinas e equipamentos \\
\hline EscInformat & Fabricação de equipamentos de informática, produtos eletrônicos e ópticos \\
\hline MqEletrico & Fabricação de máquinas e equipamentos elétricos \\
\hline MaqEquip & Fabricação de máquinas e equipamentos mecânicos \\
\hline AutomUtil & Fabricação de automóveis, caminhões e ônibus, exceto peças \\
\hline
\end{tabular}




\section{ANEXO A \\ Lista de setores do modelo}

\begin{tabular}{|c|c|}
\hline Siglas & Descriçáo do setor \\
\hline PecVeicAut & Fabricação de peças e acessórios para veículos automotores \\
\hline OtEqTransp & Fabricação de outros equipamentos de transporte, exceto veículos automotores \\
\hline IndDiversas & Fabricação de móveis e de produtos de indústrias diversas \\
\hline ManRepMqEq & Manutenção, reparação e instalação de máquinas e equipamentos \\
\hline EletriGasUt & Energia elétrica, gás natural e outras utilidades \\
\hline AguaEsgosto & Água, esgoto e gestão de resíduos \\
\hline Construcao & Construção \\
\hline Comercio & Comércio por atacado e varejo \\
\hline Terrestre & Transporte terrestre \\
\hline Aquaviario & Transporte aquaviário \\
\hline Aereo & Transporte aéreo \\
\hline ArmAuxTr & Armazenamento, atividades auxiliares dos transportes e correio \\
\hline AlojHoteis & Alojamento \\
\hline ServAlim & Alimentação \\
\hline EdicaoImp & Edição e edição integrada à impressão \\
\hline TvRadioCine & Atividades de televisão, rádio, cinema e gravação/edição de som e imagem \\
\hline Telecom & Telecomunicações \\
\hline DenSistema & Desenvolvimento de sistemas e outros serviços de informação \\
\hline InFinanSeg & Intermediação financeira, seguros e previdência complementar \\
\hline AlugImobi & Atividades imobiliárias \\
\hline JuridCont & Atividades jurídicas, contábeis, consultoria e sedes de empresas \\
\hline ArquitEngen & Serviços de arquitetura, engenharia, testes/análises técnicas e P\&D \\
\hline OtAtTecnCien & Outras atividades profissionais, científicas e técnicas \\
\hline AlugueisNImo & Aluguéis não-imobiliários e gestão de ativos de propriedade intelectual \\
\hline OtAdmin & Outras atividades administrativas e serviços complementares \\
\hline VigSegur & Atividades de vigilância, segurança e investigação \\
\hline AdmPubSegS & Administração pública, defesa e seguridade social \\
\hline EducPublic & Educação pública \\
\hline EducPriv & Educação privada \\
\hline SaudePublic & Saúde pública \\
\hline SaudePriv & Saúde privada \\
\hline ArtesCultE & Atividades artísticas, criativas e de espetáculos \\
\hline OrgAssocia & Organizaçóes associativas e outros serviços pessoais \\
\hline SvDomestic & Serviços domésticos \\
\hline
\end{tabular}


ANEXO B

Lista de produtos do modelo

\begin{tabular}{|c|c|c|c|}
\hline Produto & Descriçáo SCN 127 & Produto & Descriçãa SCN 127 \\
\hline ArrozTrig & Arroz, trigo e outros cereais & Cimento & Cimento \\
\hline Milho & Milho em grão & ArtCimGesso & $\begin{array}{l}\text { Artefatos de cimento, gesso } \\
\text { e semelhantes }\end{array}$ \\
\hline Algodao & $\begin{array}{l}\text { Algodão herbáceo, outras } \\
\text { fibras da lav. temporária }\end{array}$ & VidrosNmet & $\begin{array}{l}\text { Vidros, cerâmicos e outros } \\
\text { prod. de minerais não- } \\
\text {-metálicos }\end{array}$ \\
\hline CanaAcu & Cana-de-açúcar & FerroGusa & Ferro-gusa e ferroligas \\
\hline Soja & Soja em grão & SemiAcAco & $\begin{array}{l}\text { Semi-acabacados, lamina- } \\
\text { dos planos, longos e tubos } \\
\text { de aço }\end{array}$ \\
\hline OtLavoTp & $\begin{array}{l}\text { Outros produtos e serviços } \\
\text { da lavoura temporária }\end{array}$ & MetaluMnF & $\begin{array}{l}\text { Produtos da metalurgia de } \\
\text { metais não-ferrosos }\end{array}$ \\
\hline Laranja & Laranja & FunAcoMnF & $\begin{array}{l}\text { Peças fundidas de aço e de } \\
\text { metais náo ferrosos }\end{array}$ \\
\hline Caf & Café em grão & PdMetal & $\begin{array}{l}\text { Produtos de metal, excl. } \\
\text { máquinas e equipamentos }\end{array}$ \\
\hline OtLavoPr & $\begin{array}{l}\text { Outros produtos da lavoura } \\
\text { permanente }\end{array}$ & CompEletron & Componentes eletrônicos \\
\hline Bovinos & $\begin{array}{l}\text { Bovinos e outros animais } \\
\text { vivos, prods. animal, caça } \\
\text { e serv. }\end{array}$ & InformaEscr & $\begin{array}{l}\text { Máquinas para escritório e } \\
\text { equip. de informática }\end{array}$ \\
\hline Leite & $\begin{array}{l}\text { Leite de vaca e de outros } \\
\text { animais }\end{array}$ & $\begin{array}{l}\text { EletronCo- } \\
\text { mun }\end{array}$ & $\begin{array}{l}\text { Material eletrônico e } \\
\text { equip. de comunicaçóes }\end{array}$ \\
\hline Suinos & Suínos & EqMedOptic & $\begin{array}{l}\text { Equip. de medida, teste e } \\
\text { controle, ópticos e eletro- } \\
\text { médicos }\end{array}$ \\
\hline AvesOv & Aves e ovos & MqApEletrico & $\begin{array}{l}\text { Máquinas, aparelhos e } \\
\text { materiais elétricos }\end{array}$ \\
\hline PrExploF & $\begin{array}{l}\text { Produtos da exploração } \\
\text { florestal e da silvicultura }\end{array}$ & Eletrodomest & Eletrodomésticos \\
\hline PescaAq & $\begin{array}{l}\text { Pesca e aquicultura (peixe, } \\
\text { crustáceos e moluscos) }\end{array}$ & Tratores & $\begin{array}{l}\text { Tratores e outras máquinas } \\
\text { agrícolas }\end{array}$ \\
\hline CarvaoMin & Carvão mineral & $\begin{array}{l}\text { MqExtrM- } \\
\text { Con }\end{array}$ & $\begin{array}{l}\text { Máquinas para a extração } \\
\text { mineral e a construção }\end{array}$ \\
\hline Mnmetalic & Minerais não metálicos & $\begin{array}{l}\text { OtMqEq- } \\
\text { Meca }\end{array}$ & $\begin{array}{l}\text { Outras máquinas e equipa- } \\
\text { mentos mecânicos }\end{array}$ \\
\hline
\end{tabular}




\section{ANEXO B}

Lista de produtos do modelo

\begin{tabular}{|c|c|c|c|}
\hline Produto & Descriçáo SCN 127 & Produto & Descriçáo SCN 127 \\
\hline PetrolGas & $\begin{array}{l}\text { Petróleo, gás natural e servi- } \\
\text { ços de apoio }\end{array}$ & AutomUtil & $\begin{array}{l}\text { Automóveis, camionetas e } \\
\text { utilitários }\end{array}$ \\
\hline MinFerro & Minério de ferro & $\begin{array}{l}\text { Caminhoe- } \\
\text { sOni }\end{array}$ & $\begin{array}{l}\text { Caminhóes e ônibus, incl. } \\
\text { cabines, carrocerias e re- } \\
\text { boques }\end{array}$ \\
\hline Mnferro & $\begin{array}{l}\text { Minerais metálicos não- } \\
\text {-ferrosos }\end{array}$ & PecVeicAut & $\begin{array}{l}\text { Peças e acessórios para } \\
\text { veículos automotores }\end{array}$ \\
\hline CarneBov & $\begin{array}{l}\text { Carne de bovinos e outros } \\
\text { prod. de carne }\end{array}$ & Aeronaves & $\begin{array}{l}\text { Aeronaves, embarcações e } \\
\text { outros equipamentos de } \\
\text { transporte }\end{array}$ \\
\hline CarneSuin & Carne de suíno & Moveis & Móveis \\
\hline CarneAves & Carne de aves & IndDiversas & $\begin{array}{l}\text { Produtos de industrias } \\
\text { diversas }\end{array}$ \\
\hline PescInd & Pescado industrializado & $\begin{array}{l}\text { ManRe- } \\
\text { pMqEq }\end{array}$ & $\begin{array}{l}\text { Manutenção, reparação e } \\
\text { instalação de máquinas e } \\
\text { equipamentos }\end{array}$ \\
\hline LeiteResf & $\begin{array}{l}\text { Leite resfriado, esterilizado e } \\
\text { pasteurizado }\end{array}$ & EletriGasUt & $\begin{array}{l}\text { Eletricidade, gás e outras } \\
\text { utilidades }\end{array}$ \\
\hline OutLatic & Outros produtos do laticínio & AguaEsgRes & $\begin{array}{l}\text { Água, esgoto, reciclagem e } \\
\text { gestão de resíduos }\end{array}$ \\
\hline Acucar & Açúcar & Edificacoes & Edificaçôes \\
\hline ConFrutas & $\begin{array}{l}\text { Conservas de frutas, legu- } \\
\text { mes, outros vegetais e sucos } \\
\text { de frutas }\end{array}$ & ObInfraEstru & Obras de infra-estrutura \\
\hline OleoVegAn & $\begin{array}{l}\text { Óleos e gorduras vegetais e } \\
\text { animais }\end{array}$ & ServConstr & $\begin{array}{l}\text { Serviços especializados para } \\
\text { construçáa }\end{array}$ \\
\hline CafeBenef & Café beneficiado & Comercio & $\begin{array}{l}\text { Comércio por atacado e } \\
\text { varejo }\end{array}$ \\
\hline ArrozBene & $\begin{array}{l}\text { Arroz beneficiado e produ- } \\
\text { tos derivados do arroz }\end{array}$ & TrTerr & Transporte terrestre \\
\hline PdDTrigo & $\begin{array}{l}\text { Produtos derivados do trigo, } \\
\text { mandioca ou milho }\end{array}$ & TrTPas & Transporte de passageiros \\
\hline RacoesAni & $\begin{array}{l}\text { Raçóes balanceadas para } \\
\text { animais }\end{array}$ & TAquav & Transporte aquaviário \\
\hline
\end{tabular}




\section{ANEXO B}

Lista de produtos do modelo

\begin{tabular}{|c|c|c|c|}
\hline Produto & Descrição SCN 127 & Produto & Descrição SCN 127 \\
\hline OtPdAlim & Outros produtos alimentares & TAereo & Transporte aéreo \\
\hline Bebidas & Bebidas & ArmAuxTr & $\begin{array}{l}\text { Armazenamento e serviços } \\
\text { auxiliares aos transportes }\end{array}$ \\
\hline PdFumo & Produtos do fumo & Correios & $\begin{array}{l}\text { Correio e outros serviços } \\
\text { de entrega }\end{array}$ \\
\hline PTexteis & $\begin{array}{l}\text { Fios e fibras têxteis benefi- } \\
\text { ciadas }\end{array}$ & AlojHoteis & $\begin{array}{l}\text { Serviços de alojamento em } \\
\text { hotéis e similares }\end{array}$ \\
\hline Tecidos & Tecidos & ServAlim & Serviços de alimentação \\
\hline ArTexteis & $\begin{array}{l}\text { Art. têxteis de uso domésti- } \\
\text { co e outros têxteis }\end{array}$ & LivroJorn & Livros, jornais e revistas \\
\hline AVestuario & $\begin{array}{l}\text { Artigos do vestuário e aces- } \\
\text { sórios }\end{array}$ & $\begin{array}{l}\text { RadCineMu- } \\
\text { sic }\end{array}$ & $\begin{array}{l}\text { Serviços cinematográficos, } \\
\text { música, rádio e televisão }\end{array}$ \\
\hline CalcCouro & $\begin{array}{l}\text { Calçados e artefatos de } \\
\text { couro }\end{array}$ & Telecom Tv & $\begin{array}{l}\text { Telecomunicaçóes, TV por } \\
\text { assinatura e outros serv. } \\
\text { Relacionados }\end{array}$ \\
\hline PdMadeira & $\begin{array}{l}\text { Produtos de madeira, exclu- } \\
\text { sive móveis }\end{array}$ & DenSistema & $\begin{array}{l}\text { Desenvolvimento de sis- } \\
\text { temas e outros serviços de } \\
\text { informação }\end{array}$ \\
\hline Celulose & Celulose & InFinancSegu & $\begin{array}{l}\text { Intermediação financeira, } \\
\text { seguros e previdência com- } \\
\text { plementar }\end{array}$ \\
\hline Papel & $\begin{array}{l}\text { Papel, papelão, embalagens } \\
\text { e artefatos de papel }\end{array}$ & AlugImobi & $\begin{array}{l}\text { Aluguel efetivo e serviços } \\
\text { imobiliários }\end{array}$ \\
\hline Impressao & $\begin{array}{l}\text { Serviços de impressão e } \\
\text { reproduçáo }\end{array}$ & AlugImput & Aluguel imputado \\
\hline CombAviac & Combustíveis para aviação & JuridCont & $\begin{array}{l}\text { Serviços jurídicos, contabi- } \\
\text { lidade e consultoria }\end{array}$ \\
\hline Gasoalcool & Gasoálcool & PesqDes & $\begin{array}{l}\text { Pesquisa e desenvolvimen- } \\
\text { to }\end{array}$ \\
\hline NaftasPetr & Naftas para petroquímica & ArquitEngen & $\begin{array}{l}\text { Serviços de arquitetura e } \\
\text { engenharia }\end{array}$ \\
\hline $\begin{array}{l}\text { OleoCom- } \\
\text { bust }\end{array}$ & Óleo combustível & Publicidade & $\begin{array}{l}\text { Publicidade e outros servi- } \\
\text { ços técnicos }\end{array}$ \\
\hline DieselBio & Diesel - biodiesel & AlugNImo & $\begin{array}{l}\text { Aluguéis não-imob. e ges- } \\
\text { tão de ativos de proprieda- } \\
\text { de intelectual }\end{array}$ \\
\hline
\end{tabular}




\section{ANEXO B}

Lista de produtos do modelo

\begin{tabular}{|c|c|c|c|}
\hline Produto & Descrição SCN 127 & Produto & Descriçáo SCN 127 \\
\hline ORfPetroleo & $\begin{array}{l}\text { Outros produtos do refino } \\
\text { do petróleo }\end{array}$ & CondoEdific & $\begin{array}{l}\text { Condomínios e serviços } \\
\text { para edifícios }\end{array}$ \\
\hline EtanolComb & $\begin{array}{l}\text { Etanol e outros biocombus- } \\
\text { tíveis }\end{array}$ & OtServAdm & $\begin{array}{l}\text { Outros serviços adminis- } \\
\text { trativos }\end{array}$ \\
\hline QuimInorg & $\begin{array}{l}\text { Produtos químicos inorgâ- } \\
\text { nicos }\end{array}$ & VigSegur & $\begin{array}{l}\text { Serviços de vigilância, se- } \\
\text { gurança e investigação }\end{array}$ \\
\hline AdubosFer & Adubos e fertilizantes & AdmPublica & $\begin{array}{l}\text { Serviços coletivos da admi- } \\
\text { nistração pública }\end{array}$ \\
\hline QuimOrgani & $\begin{array}{l}\text { Produtos químicos orgâni- } \\
\cos \end{array}$ & PrevAsSocial & $\begin{array}{l}\text { Serviços de previdência e } \\
\text { assistência social }\end{array}$ \\
\hline ResinasFib & $\begin{array}{l}\text { Resinas,elastômeros e fibras } \\
\text { artif. e sintéticas }\end{array}$ & EducPublic & Educação pública \\
\hline DefAgrico & $\begin{array}{l}\text { Defensivos agrícolas e desin- } \\
\text { festantes domissanitários }\end{array}$ & EducPriv & Educação privada \\
\hline QuimicDiv & Produtos químicos diversos & SaudePublic & Saúde pública \\
\hline TintasVer & $\begin{array}{l}\text { Tintas, vernizes, esmaltes e } \\
\text { lacas }\end{array}$ & SaudePriv & Saúde privada \\
\hline PerfumLimp & $\begin{array}{l}\text { Perfumaria, sabóes e artigos } \\
\text { de limpeza }\end{array}$ & ArtesCultE & $\begin{array}{l}\text { Serviços de artes, cultura, } \\
\text { esporte e recreação }\end{array}$ \\
\hline Farmac & Produtos farmacêuticos & OgPatrSind & $\begin{array}{l}\text { Organizaçóes patronais, } \\
\text { sindicais e outros serviços } \\
\text { associativos }\end{array}$ \\
\hline ABorracha & Artigos de borracha & $\begin{array}{l}\text { ManComp- } \\
\text { Tele }\end{array}$ & $\begin{array}{l}\text { Manutenção de computa- } \\
\text { dores, telefones e objetos } \\
\text { domésticos }\end{array}$ \\
\hline \multirow[t]{2}{*}{ APlastico } & Artigos de plástico & SvPessoais & Serviços pessoais \\
\hline & & SvDomestic & Serviços domésticos \\
\hline
\end{tabular}

